\title{
RECEIVED
}

\section{Procedures for Two-Dimensional Electrophoresis of Proteins}

\section{FEB 121997 \\ OSTI}

Sandra L. Tollaksen and Carol S. Giometti
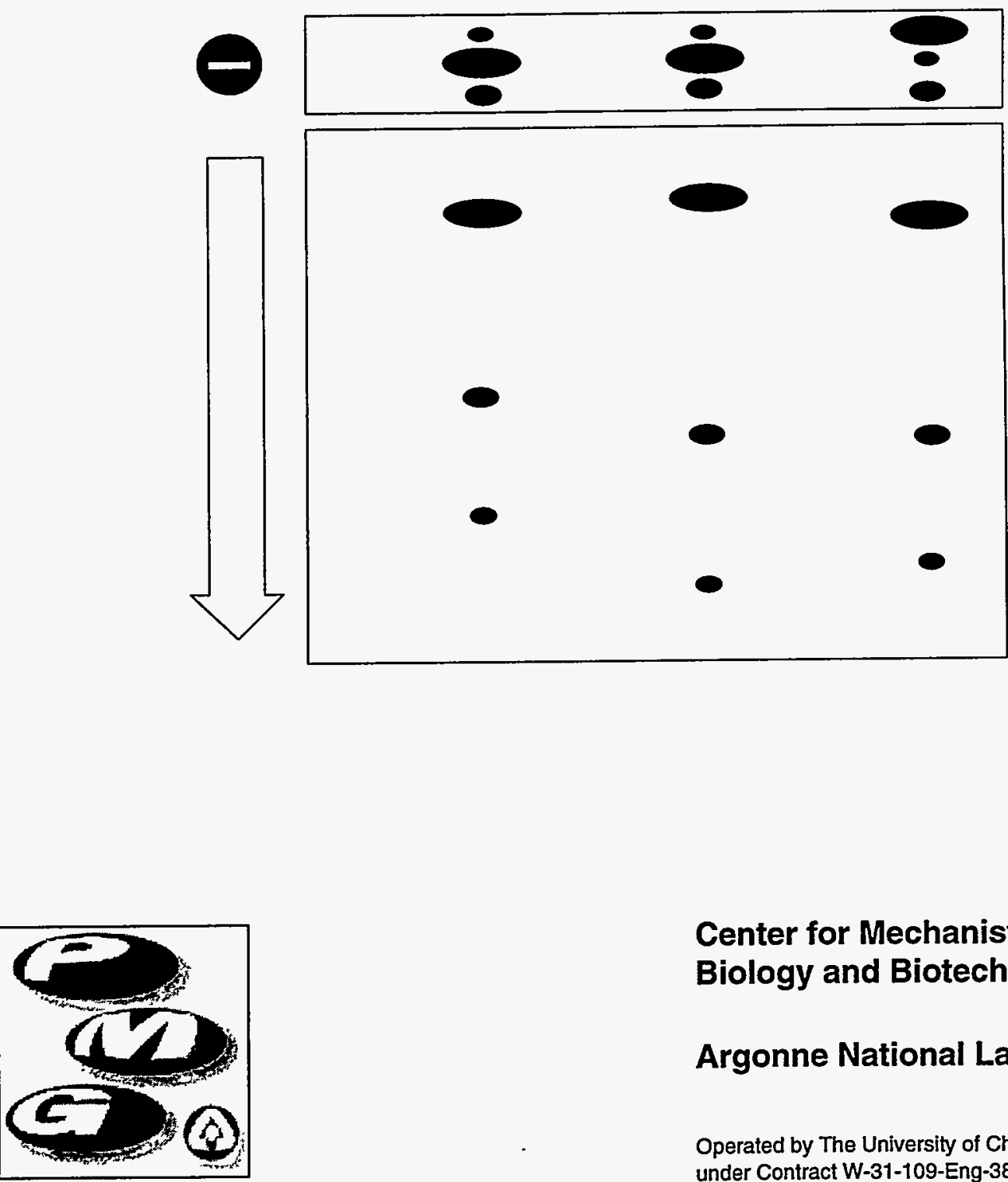

Center for Mechanistic

Biology and Biotechnology

Argonne National Laboratory

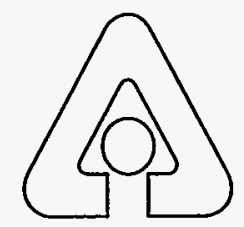

Operated by The University of Chicago, under Contract W-31-109-Eng-38, for the

United States Department of Energy 


\section{Argonne National Laboratory}

Argonne National Laboratory, with facilities in the states of Illinois and Idaho, is owned by the United States Govemment, and operated by the University of Chicago under the provisions of a contract with the Department of Energy.

This technical report is a product of Argonne's Energy Systems Division.

For information on the division's scientific and engineering activities, contact:

Director, Energy Systems Division

Argonne National Laboratory

Argonne, Illinois 60439-4815

Telephone (708) 252-3724

Publishing support services were provided by Argonne's Information and Publishing Division (for more information, see IPD's home page: http://www.jpd.anl.gov/).

\section{Disclaimer}

This report was prepared as an account of work sponsored by an agency of the United States Government. Neither the United States Government nor any agency thereof, nor any of their employees, makes any warranty, express or implied, or assumes any legal liability or responsibility for the accuracy, completeness, or usefulness of any information, apparatus, product, or process disclosed, or represents that its use would not infringe privately owned rights. Reference herein to any specific commercial product, process, or service by trade name, trademark, manufacturer, or otherwise, does not necessarily constitute or imply its endorsement, recommendation, or favoring by the United States Government or any agency thereof. The views and opinions of authors expressed herein do not necessarily state or reflect those of the United States Government or any agency thereof.

Reproduced directly from the best available copy.

Available to DOE and DOE contractors from the Office of Scientific and Technical Information, P.O. Box 62, Oak Ridge, TN 37831; prices available from (423) 576-8401.

Available to the public from the National Technical Information Service, U.S. Department of Commerce, 5285 Port Royal Road, Springfield, VA 22161. 


\section{Procedures for Two-Dimensional Electrophoresis of Proteins}

by S.L. Tollaksen and C.S. Giometti

Protein Mapping Group, Center for Mechanistic Biology and Biotechnology, Argonne National Laboratory, 9700 South Cass Avenue, Argonne, Illinois 60439

\section{DISCLAIMER}

This report was prepared as an account of work sponsored by an agency of the United States Government. Neither the United States Government nor any agency thereof, nor any of their employees, makes any warranty, express or implied, or assumes any legal liability or responsibility for the accuracy, completeness, or usefulness of any information, apparatus, product, or process disclosed, or represents that its use would not infringe privately owned rights. Reference herein to any specific commercial product, process, or service by trade name, trademark, manufacturer, or otherwise does not necessarily constitute or imply its endorsement, recommendation, or favoring by the United States Government or any agency thereof. The views and opinions of authors expressed herein do not necessarily state or reflect those of the United States Government or any agency thereof.

\section{October 1996}

Work sponsored by the United States Department of Energy, Office of Health and Environmental Research, under Contract W-31-109-Eng-38 


\section{DISCLAIMER}

Portions of this document may be illegible in electronic image products. Images are produced from the best available original document. 


\section{CONTENTS}

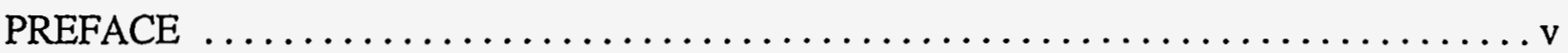

ACKNOWLEDGMENT $\ldots \ldots \ldots \ldots \ldots \ldots \ldots \ldots \ldots \ldots \ldots \ldots \ldots \ldots \ldots \ldots \ldots \ldots$ vi

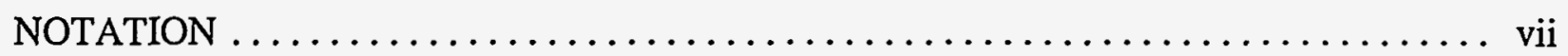

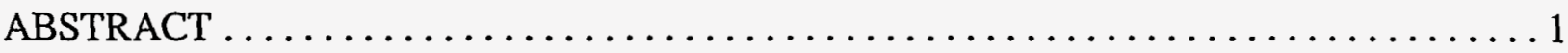

1 SAMPLE PREPARATION $\ldots \ldots \ldots \ldots \ldots \ldots \ldots \ldots \ldots \ldots \ldots \ldots \ldots \ldots \ldots \ldots \ldots \ldots \ldots \ldots \ldots$

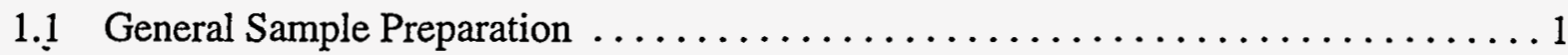

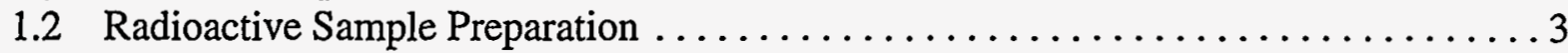

1.2.1 Safety and Waste Management Procedures $\ldots \ldots \ldots \ldots \ldots \ldots \ldots \ldots \ldots \ldots \ldots$

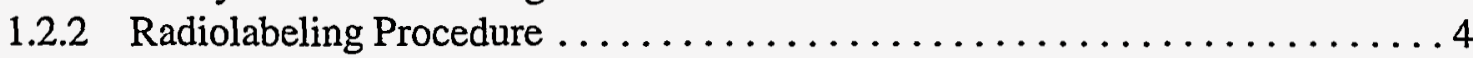

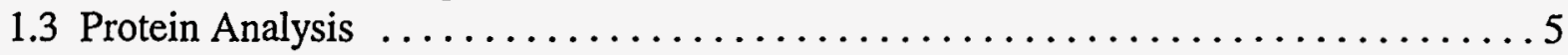

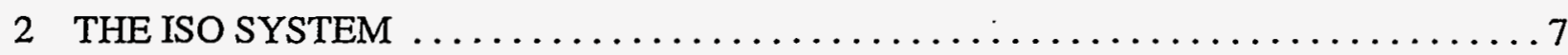

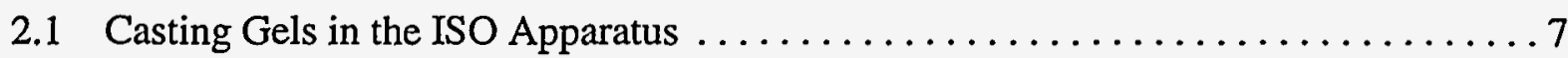

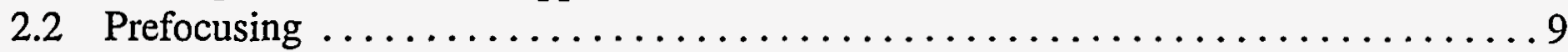

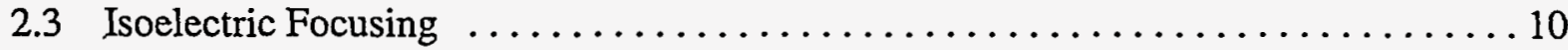

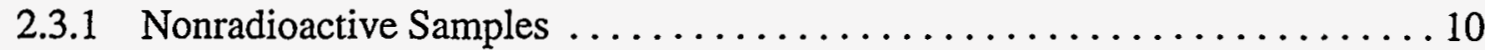

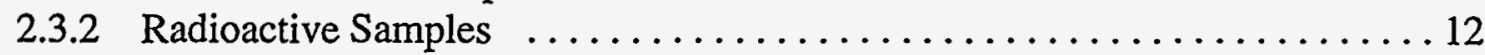

2.4 Non-Equilibrium $\mathrm{pH}$ Gradient Electrophoresis $\ldots \ldots \ldots \ldots \ldots \ldots \ldots \ldots \ldots \ldots \ldots \ldots \ldots \ldots$

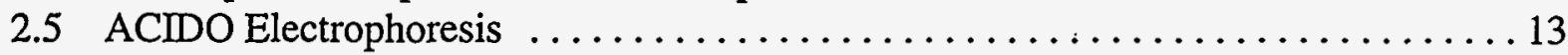

2.6 ISO/BASO Gel Recovery and Equilibration $\ldots \ldots \ldots \ldots \ldots \ldots \ldots \ldots \ldots \ldots \ldots \ldots \ldots \ldots$

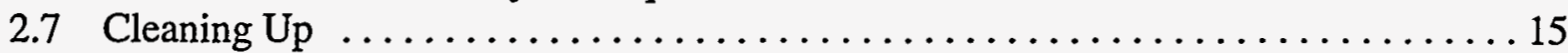

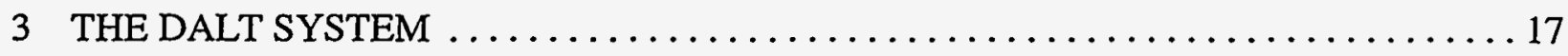

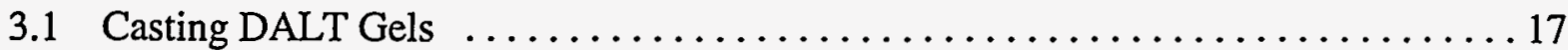

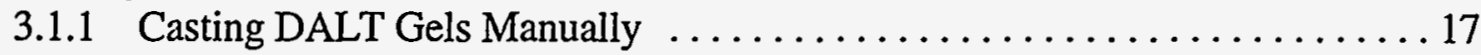

3.1.2 Casting DALT Gels with Computer Assistance ................ 20

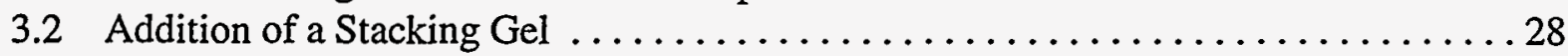

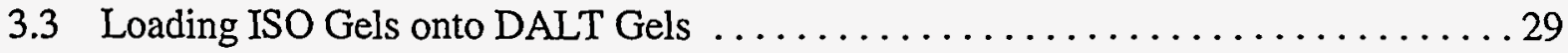

3.4 Running the DALT Electrophoresis System . . . . . . . . . . . . . . . . . 31

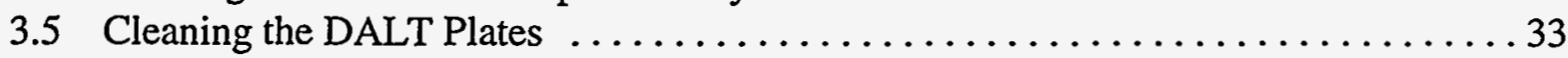

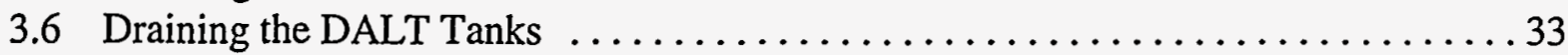

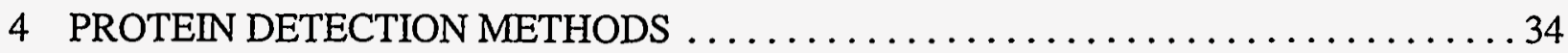

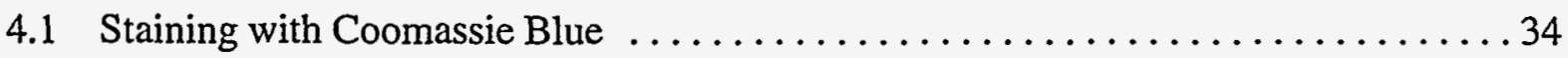

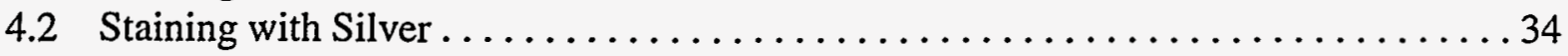




\section{CONTENTS (Cont.)}

4.2.1 Hints for Silver Staining . . . . . . . . . . . . . . . . . . . . . . . . . 34

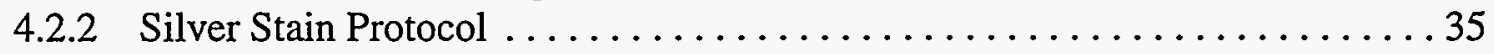

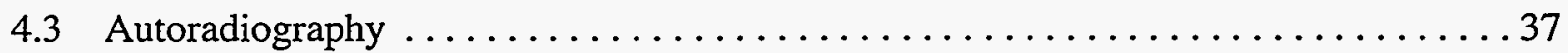

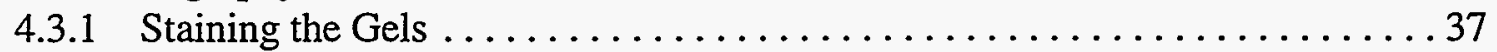

4.3.2 Drying the Gels Using the Virtis Freezemobile and the BioRad Gel Dryer ............................... 37

4.3.3 Loading the Dried Gels onto Film $\ldots \ldots \ldots \ldots \ldots \ldots \ldots \ldots \ldots \ldots$

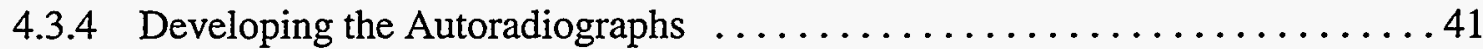

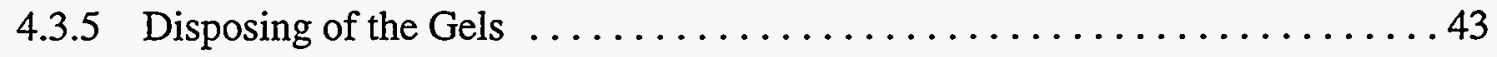

5 PHOTOGRAPHIC TECHNIQUES $\ldots \ldots \ldots \ldots \ldots \ldots \ldots \ldots \ldots \ldots \ldots \ldots \ldots \ldots \ldots \ldots \ldots \ldots \ldots$

5.1 Photographing Gels $\ldots \ldots \ldots \ldots \ldots \ldots \ldots \ldots \ldots \ldots \ldots \ldots \ldots \ldots \ldots$

5.2 Developing Film Using the Hope Film Processor Model

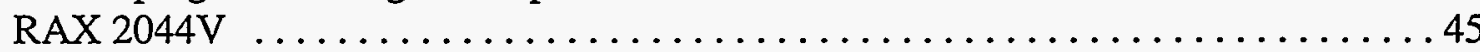

5.3 Printing with the Ilfolab Model $2150 \mathrm{RC}$ Printer $\ldots \ldots \ldots \ldots \ldots \ldots \ldots \ldots$

6 TRANSFER OF PROTEINS FROM 2DE GELS TO PVDF MEMBRANES $\ldots \ldots \ldots \ldots 0$

6.1 Transferring the Proteins to Membranes ........................ 50

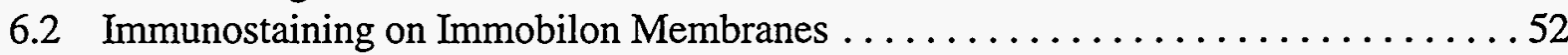

6.3 Amino Terminal Amino Acid Sequencing . ....................... 53

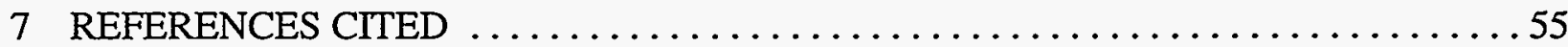

8 SELECTED REFERENCES FROM ARGONNE 2DE RESEARCH $\ldots \ldots \ldots \ldots \ldots 56$

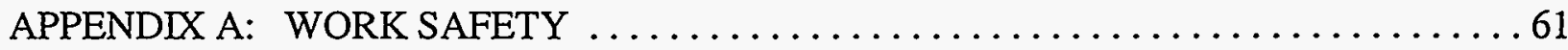

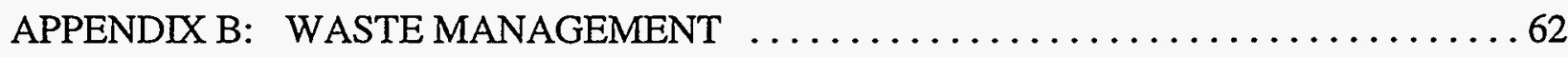

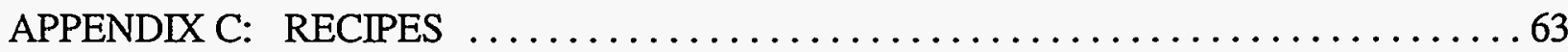

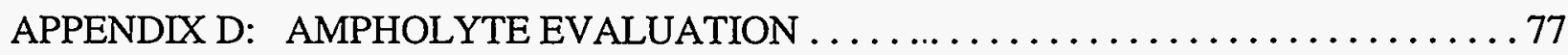

APPENDIX E: MISCELLANEOUS PROCEDURES $\ldots \ldots \ldots \ldots \ldots \ldots \ldots \ldots \ldots \ldots$

FIGURE

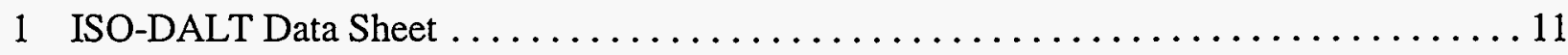




\section{PREFACE}

High-resolution two-dimensional gel electrophoresis (2DE) of proteins, using isoelectric focusing in the first dimension and sodium dodecyl sulfate/polyacrylamide gel electrophoresis (SDS-PAGE) in the second, was first described in 1975 by O'Farrell (Journal of Biological Chemistry 250:4007-4021, 1975) and Klose (Archives of Toxicology 38:53-60, 1977). In the 20 years since those publications, numerous modifications of the original method have evolved. The ISO-DALT system of 2DE, developed by Norman and Leigh Anderson at Argonne National Laboratory (Anderson, N.G., and N.L. Anderson, Analytical Biochemistry 85:331-340, 1978, and Anderson, N.L., and N.G. Anderson, Analytical Biochemistry 85:341-354, 1978), is a highthroughput approach that has stood the test of time. The problem of casting many isoelectric focusing gels and SDS-PAGE slab gels (up to 20) in a reproducible manner has been solved by the use of the techniques and equipment described in this manual. It is fitting to publish a revised manual of the 2DE procedures currently used at Argonne coincidental with the twentieth anniversary of $2 \mathrm{DE}$ and the fiftieth anniversary of Argonne. In addition to more current recipes and electrophoresis procedures than those in the previous editions of the manual, this version incorporates a description of required safety and waste handling procedures.

Although some disagreement still exists on this point, the authors recommend that gel patterns be oriented with acid isoelectric points (pI's) to the left and high sodium dodecyl sulfate (SDS) molecular weights at the top. This results in a system of $\mathrm{pI}$ and molecular weight values that run according to the Cartesian convention and facilitates the use of the charge and molecular weight standards described herein. The preceding reports in this series are ANL-BIM-79-2, September 1979; ANL-BIM-81-1, October 1981; and ANL-BIM-84-1, May 1984.

The two authors have 37 combined years of work in this field and have run more than 45,000 gels! This manual is dedicated to our mentor, Dr. Norman G. Anderson, who taught us the $2 \mathrm{DE}$ technique and without whom we would not be in this field. 


\section{ACKNOWLEDGMENT}

The authors thank Lisa M. Kattan for primary technical editing of the manuscript and David E. Nadziejka for additional editing and preparing the manuscript for publication. 


\section{NOTATION}

\section{Abbreviations}

2DE

ACIDO

BASO

bis

CAPS

conc.

DALT

DTE

DTT

$f$

ISO

NP-40

pI

PVDF

SDS

TEMED

Tris two-dimensional gel electrophoresis

isoelectric focusing (gels or procedure) for acidic proteins isoelectric focusing (gels or procedure) for basic proteins

$N, N^{\prime}$-methylene-bis-acrylamide

3-(cyclohexylamino)-1-propanesulfonic acid

concentration

second-dimension electrophoresis (gels or procedure)

dithioerythritol

dithiothreitol

f-stop

isoelectric focusing (gels or procedure)

Nonidet P-40

isoelectric point

polyvinylidene difluoride

sodium dodecyl sulfate

$N, N, N^{\prime}, N^{\prime}$-tetramethylethylenediamine

2-amino-2-(hydroxymethyl)-1,3-propanediol

\section{Chemical formulae}

$\mathrm{HCl}$ hydrochloric acid

$\mathrm{Hg}$ mercury

$\mathrm{H}_{3} \mathrm{PO}_{4} \quad$ phosphoric acid

$\mathrm{NaOH}$ sodium hydroxide

$\left(\mathrm{NH}_{4}\right)_{2} \mathrm{~S}_{2} \mathrm{O}_{8} \quad$ ammonium persulfate

$\mathrm{P}$ phosphorus

S sulfur 


\section{Units}

$\begin{array}{ll}{ }^{\circ} \mathrm{C} & \text { degree Celsius } \\ \mathrm{A} & \text { ampere } \\ \mathrm{cm} & \text { centimeter } \\ \mathrm{g} & \text { gram } \\ \mathrm{g} & \text { acceleration due to gravity } \\ \mathrm{gal} & \text { gallon } \\ \mathrm{h} & \text { hour } \\ \mathrm{in} . & \text { inch } \\ \mathrm{kg} & \text { kilogram } \\ \mathrm{L} & \text { liter } \\ \mathrm{M} & \text { molar } \\ \mathrm{mA} & \text { milliampere } \\ \mathrm{mCi} & \text { millicurie } \\ \mathrm{mg} & \text { milligram } \\ \mathrm{min} & \text { minute } \\ \mathrm{mL} & \text { milliliter } \\ \mathrm{mm} & \text { millimeter } \\ \mathrm{mM} & \text { millimolar } \\ \mathrm{mT} & \text { millitorr } \\ \mu \mathrm{g} & \text { microgram } \\ \mu \mathrm{L} & \text { microliter } \\ \mathrm{N} & \text { normal } \\ \mathrm{nm} & \text { nanometer } \\ \mathrm{Pa} & \text { pascal } \\ \mathrm{rpm} & \text { revolutions per minute } \\ \mathrm{s} & \text { second } \\ \mathrm{V} & \text { volt } \\ \mathrm{v} / \mathrm{v} & \text { volume per unit volume } \\ \mathrm{W} & \text { watt } \\ \mathrm{w} / \mathrm{v} & \text { weight per unit volume } \\ & \end{array}$




\title{
PROCEDURES FOR TWO-DIMENSIONAL ELECTROPHORESIS OF PROTEINS
}

\author{
Sandrà L. Tollaksen and Carol S. Giometti
}

\begin{abstract}
The ISO-DALT system of two-dimensional gel electrophoresis originated in the late 1970 s and has been modified many times to improve its - high-resolution, high-throughput capabilities. This report provides the detailed procedures used with the current ISO-DALT system to prepare, run, stain, and photograph two-dimensional gels for protein analysis.
\end{abstract}

\section{SAMPLE PREPARATION .}

The first step in preparing a sample of cells or tissue for two-dimensional gel electrophoresis (2DE) analysis is to mix the sample with a solubilization solution composed of a detergent, a reducing agent, and an ampholyte. The detergent (e.g., Nonidet P-40, sodium dodecyl sulfate) ruptures cell membranes, allowing the release of the cell contents, including proteins, into solution. The reducing agent (e.g., 2-mercaptoethanol, dithiothreitol) and denaturants such as urea disrupt covalent and hydrogen bonds, denaturing the proteins. Ampholytes protect the proteins from proteolysis by acting as a buffer, and they also bind to DNA. The solubilization solution used depends upon the type of sample to be analyzed.

General work safety and waste management practices at Argonne are outlined in Appendices A and B. Specific warnings, cautions, and notes on safety and waste handling are found in the procedures throughout this manual.

\subsection{GENERAL SAMPLE PREPARATION}

The solutions included in this manual (see Appendix $C$ for recipes) can be made in fairly large quantities (up to $1 \mathrm{~L}$ ) and stored frozen at $-70^{\circ} \mathrm{C}$ in microfuge tubes in small aliquots $(1,10$, or $50 \mathrm{~mL}$ ). The following four solutions for sample preparation have been optimized for the samples specified. Experimentation with these methods and chemicals is advised to find the best mixture for 
other types of samples. Samples that are prepared in the following sodium dodecyl sulfate (SDS) or urea mixes may be stored at $-70^{\circ} \mathrm{C}$, thawed, and reused.

1. SDS mix (recipe 1). This mix is useful for body fluids such as serum, plasma, or amniotic fluid. To a $10-\mu \mathrm{L}$ sample, add $20-30 \mu \mathrm{L}$ of SDS mix. Next, heat the sample on a $95^{\circ} \mathrm{C}$ heating block for $5 \mathrm{~min}$ to achieve maximum solubilization and to inactivate the proteolytic enzymes.

\section{CAUTION}

- For mixes containing $9 \mathrm{M}$ urea ( $\# 2,3$, and 4, immediately below), use 1.5 -mL polyallomer centrifuge tubes. Do not use polycarbonate tubes with mixes containing $9 \mathrm{M}$ urea because the tubes may crack.

- Do not heat protein samples in the presence of urea, because heat will carbamylate the protein.

2. NP-40/urea mix (recipe 2). This mix works well with solid tissue samples and tissuecultured cells. For a wet tissue sample, use a volume of mix which is eight times the blotted wet weight of the sample (e.g., for a 100-mg sample, use $800 \mu \mathrm{L}$ of mix). For a frozen tissue sample, pulverize the sample on a platform chilled on dry ice and use a volume of mix which is four times the weight of the powdered sample. Homogenize (or sonicate) before centrifuging the sample. For tissue-cultured cells where Coomassie blue staining will be used, use $6 \times 10^{4}$ cells per milliliter of mix; when gels will be silver-stained, use $5 \times 10^{3}$ cells per milliliter of mix. When solubilizing cells, disperse the cell pellet by tapping the bottom of the tube gently prior to adding the solubilization mix. After the mix is added, mix the cell lysate well by drawing the solution up and down in a pipette tip, using an Eppendorf or Pipetman. Ten to thirty microliters of this urea mix may also be mixed with $10 \mu \mathrm{L}$ of a concentrated liquid protein sample. The tissue and tissue-culture samples contain DNA and cell debris that can be sedimented by centrifugation. (DNA in the sample causes broken ISO gels and/or streaks on the DALT gels.) Samples may be spun at $22{ }^{\circ} \mathrm{C}$ for $1 \mathrm{~h}$ at approximately $100,000 \times g$ in an ultracentrifuge or in a Beckman TL-100 centrifuge at $22{ }^{\circ} \mathrm{C}$ for $10 \mathrm{~min}$ at $100,000 \mathrm{rpm}(435,000 \times \mathrm{g})$. Pour off the supernatant for analysis by $2 \mathrm{DE}$ and discard the small translucent pellet.

3. Urea mix without NP-40 (recipe 3). This preparation is used for solubilizing the proteins in urine. To get the best results (fewer streaks), put $10 \mathrm{mg}$ of lyophilized urinary proteins into $100 \mu \mathrm{L}$ of the mix, centrifuge as above, and load $10 \mu \mathrm{L}$ (or less) of the solution onto the ISO gel. 
4. NP-40/urea/DTE mix (recipe 4). This preparation, which solubilizes muscle and certain other tissues well, contains $1 \%$ dithioerythritol (DTE) instead of $2 \%$ 2-mercaptoethanol. Tissue solubilization and centrifugation are as described for the NP-40/urea mix.

NOTE: All urea samples are centrifuged before being frozen for storage; after thawing, another centrifugation is recommended.

\subsection{RADIOACTIVE SAMPLE PREPARATION}

\subsubsection{Safety and Waste Management Procedures}

1. Health Physics should be notified whenever a shipment of $1 \mathrm{mCi}$ or more of isotope is received. Such sources must be stored in a refrigerator or a $-70{ }^{\circ} \mathrm{C}$ freezer in a controlled area.

2. Wear latex gloves when handling radioactive material. Magenta lab coats are required for work with isotopes in Radioactive Materials Areas (i.e., those equipped with hand and foot monitors), but regular lab coats are approved for low-level radioactive work in controlled areas.

3. Cover the work area with plastic-backed absorbent paper.

4. Use disposable pipettes and syringes whenever possible. If not possible, label equipment as to possible contamination with radioactive material and store in a controlled area.

5. Addition of isotopes to sterile cell cultures must be done within the confines of a hood approved for radioactive work. Containers of charcoal must be used to scavenge free ${ }^{35} \mathrm{~S}$.

6. Notify Health Physics several days prior to starting a radioactive experiment so they know when extra surveying is going to be needed. Request that Health Physics personnel survey laboratory benches, equipment, and floors immediately after radioactive work is completed.

7. Make an entry in the appropriate log book whenever any material is added to solid or liquid radioactive waste containers. 


\subsubsection{Radiolabeling Procedure}

\section{CAUTION}

${ }^{35} \mathrm{~S}$ by-products are extremely volatile and may be released when the stock vial is opened (see Miller 1990).

1. The L- $\left[{ }^{35}\right.$ S $]$ methionine will arrive frozen on dry ice. Place a shallow dish of charcoal, a charcoal filter, or copper wool in the hood to adsorb released activity. Before the isotope is used, thaw it and divide it into $250-\mu \mathrm{Ci}$ aliquots. Store these aliquots at $-70{ }^{\circ} \mathrm{C}$ and thaw each immediately before use.

CAUTION
All manipulations involving ${ }^{32} \mathrm{P}$ should be done behind acrylic shielding,
and labeled samples must be stored in acrylic containers.

2. Mix the isotope with the cell sample. Samples (generally mammalian cells, occasionally tissue pieces) are incubated with either L- $\left[{ }^{35} \mathrm{~S}\right]$ methionine (approximately $50 \mu \mathrm{Ci}$ per sample) or ${ }^{32} \mathrm{P}$-orthophosphate ( $200 \mu \mathrm{Ci}$ per sample) in tissue culture medium or Tris buffer for 1-18 h. This labeling procedure must be done in a hood approved for work with isotopes if sterile conditions are required. A designated area of a lab bench in a controlled area will suffice if sterility is not required.

3. Separate the cells or tissue pieces from the labeling medium by centrifuging them in capped tubes. Alternatively, cells can be separated by suction (if the cells are attached securely to the tissue culture dish) using an apparatus consisting of a vacuum pump with a regulator and an Erlenmeyer flask (to serve as a trap for radioactive liquid) connected by Tygon ${ }^{\circledR}$ tubing to a needle for aspiration of the medium, or, by simply using a Pasteur pipette. This procedure should be done within a designated area. The liquid medium, containing approximately $80 \%$ of the original isotope, is discarded into a radioactive liquid waste container. Plastic tissue culture plates, centrifuge tubes, or petri dishes used as vessels for the labeling procedure (accounting for approximately $1 \%$ of the original isotope) are discarded as low-level radioactive waste.

4. Solubilize the radioactively labeled cells (or tissues) in an aqueous solution containing $9 \mathrm{M}$ urea, 5\% 2-mercaptoethanol, 2\% ampholyte, and 4\% NP-40. Next, centrifuge the samples in a Beckman microfuge (designated for use with radioactive samples) for 8 min to pellet the DNA. After centrifugation, decant the supernatants (a total volume of $50 \mu \mathrm{L}$ containing approximately $15 \%$ of the original isotope) into microfuge tubes 
and store at $-70^{\circ} \mathrm{C}$. The samples must be clearly labeled as "RADIOACTIVE MATERIALS." The pellets and tubes in which they are contained (accounting for less than $1 \%$ of the original isotope) should be disposed of as low-level radioactive waste.

\subsection{PROTEIN ANALYSIS}

A modified Bradford protein assay (Ramagli and Rodriguez 1985) can be used to determine the protein concentration in samples mixed with NP-40/urea. This procedure is as follows:

1. Turn on the spectrophotometer at least $30 \mathrm{~min}$ before use. Use the single-wavelength, visible-spectrum lamp with the wavelength set to $595 \mathrm{~nm}$.

2. Prepare the BioRad protein assay dye reagent: Add 1 part of the reagent to 4 parts of double-distilled water, and then filter the solution through Whatman \#1 filter paper.

3. Prepare the ovalbumin protein stock solution by weighing out $125 \mathrm{mg}$ of ovalbumin and dissolving it in $25 \mathrm{~mL}$ of urea/NP-40 mix to make a $5 \mu \mathrm{g} / \mu \mathrm{L}$ stock solution. Note that the ovalbumin must be completely dissolved in this solution to serve as an accurate standard.

4. Prepare standards (dilution of ovalbumin stock solution with urea/NP-40 mix):

\begin{tabular}{ccl} 
Tube & Concentration & \multicolumn{1}{c}{ Mixture } \\
\hline Tube 0 & Blank & no stock; $1 \mathrm{~mL}$ of urea/NP-40 mix \\
Tube 1 & $2.5 \mu \mathrm{g} / 10 \mu \mathrm{L}$ & $\begin{array}{l}50 \mu \mathrm{L} \text { of stock diluted to } 1 \mathrm{~mL} \text { w } \\
\text { urea/NP-40 mix }\end{array}$ \\
Tube 2 & $5.0 \mu \mathrm{g} / 10 \mu \mathrm{L}$ & $100 \mu \mathrm{L}$ of stock diluted to $1 \mathrm{~mL}$ \\
Tube 3 & $10.0 \mu \mathrm{g} / 10 \mu \mathrm{L}$ & $200 \mu \mathrm{L}$ of stock diluted to $1 \mathrm{~mL}$ \\
Tube 4 & $15.0 \mu \mathrm{g} / 10 \mu \mathrm{L}$ & $300 \mu \mathrm{L}$ of stock diluted to $1 \mathrm{~mL}$ \\
Tube 5 & $25.0 \mu \mathrm{g} / 10 \mu \mathrm{L}$ & $500 \mu \mathrm{L}$ of stock diluted to $1 \mathrm{~mL}$ \\
Tube 6 & $35.0 \mu \mathrm{g} / 10 \mu \mathrm{L}$ & $700 \mu \mathrm{L}$ of stock diluted to $1 \mathrm{~mL}$ \\
Tube 7 & $50.0 \mu \mathrm{g} / 10 \mu \mathrm{L}$ & $1 \mathrm{~mL}$ of stock solution
\end{tabular}

5. Label clean, identical glass test tubes; place $10 \mu \mathrm{L}$ of either a sample or a standard solution in each. 
6. Add $10 \mu \mathrm{L}$ of $0.1 \mathrm{~N} \mathrm{HCl}$ and $80 \mu \mathrm{L}$ of double-distilled water to each tube.

7. Add $3.5 \mathrm{~mL}$ of the BioRad assay reagent solution (from step 2) to each of the tubes. Vortex to mix.

8. Allow the tubes to incubate at room temperature for 5-10 $\mathrm{min}$. Then pour the solution into clean disposable cuvettes.

9. Read the absorbencies at $595.0 \mathrm{~nm}$ on the Beckman DU-7 spectrophotometer. First, calibrate the spectrophotometer using the blank. Next, read the standards. Then, read the samples after 5-10 min of incubation (although absorbance readings are stable for up to an hour after the reaction has started). Use disposable cuvettes and collect the contents in a methanol waste container after reading the results. If disposable tubes or cuvettes are not used, soak the reusable tubes overnight in a dilute bleach solution, rinse them thoroughly, and let them drain dry upside down in a rack. Do not use soap or detergent to clean the test tubes used for the protein assay, because the detergent will adversely affect the assay.

10. Using the results from the standards, plot absorbance vs. micrograms of protein to produce a standard curve. If the absorbencies of the samples do not fall within the limits of the standard curve, dilute the samples and rerun. The standards may be frozen and reused several times, unless a precipitate forms. If in doubt, prepare fresh standards. 


\section{THE ISO SYSTEM}

Proteins are charged particles, their net charge dictated by their amino acid composition. In the first-dimension separation, called isoelectric focusing, proteins are separated by moving them through a pH gradient established using amphoteric molecules called ampholytes. Each protein migrates through the gradient until it reaches its isoelectric point, which is the $\mathrm{pH}$ at which the net charge of the protein is zero. In nonequilibrium techniques such as BASO and ACIDO (see below), proteins migrate through the $\mathrm{pH}$ gradient until the electrophoresis is stopped by the operator.

\subsection{CASTING GELS IN THE ISO APPARATUS}

NOTE: "Water" refers to the tap water distilled once and piped from the building's central system; "double-distilled water" refers to tap-distilled water that has been distilled one more time into glass. All solutions are made with double-distilled water, but the ISO gels are cast by displacement in tap-distilled water.

There are two ISO formats, the 7-in. $(18 \mathrm{~cm})$ and the 10 -in. $(25 \mathrm{~cm})$. The selection of ISO format should be based on optimal resolution of the proteins being analyzed. The $2 \mathrm{DE}$ work at Argonne is generally done using the 10 -in. format for isoelectric focusing and the 7-in. format for BASO-DALTs.

The entire system must be clean and dry (see Section 2.7, Cleaning Up).

1. Fill the large bottom chamber of the ISO system to the load mark ( $2 \mathrm{~L}$ for 7-in. systems and $3 \mathrm{~L}$ for 10 -in. systems) with water. Position the acrylic trough on the base of the support stand and place the upper chamber, which holds the gel tubes and the metal retainer, into the acrylic trough. 


\section{WARNING}

Preparation of stock acrylamide solutions (which are carcinogenic and neurotoxic) from crystalline chemicals must be done in the Carcinogen Laboratory. The working solution must be clearly labeled "DANGER: CANCER HAZARD" and be transported with secondary containment from the Carcinogen Lab to the laboratory where it is used. All personnel working with acrylamide must take the course on "Safe Handling of Carcinogens."

2. Prepare the acrylamide gel by mixing the following in a $150-\mathrm{mL}$ lyophilizer flask.

\begin{tabular}{|c|c|}
\hline Compound & Amount \\
\hline urea & $8.25 \mathrm{~g}$ \\
\hline $\begin{array}{l}\text { ampholytes (selection dependent on sample } \\
\text { to be analyzed) }\end{array}$ & $0.8 \mathrm{~mL}$ \\
\hline acrylamide ( $30 \%$ solution; recipe 5) & $2.0 \mathrm{~mL}$ \\
\hline double-distilled water & $6.0 \mathrm{~mL}$ \\
\hline
\end{tabular}

Dissolution, an endothermic process for urea, is aided by warming the flask and its contents in a water bath, but do not heat the urea solution beyond room temperature.

3. Degas the solution briefly using a vacuum pump dedicated for degassing acrylamide solutions. (If the solution is degassed for too long, the urea will come out of solution; if this happens, warm the flask slightly until the urea goes back into solution.)

4. For all gels except those for urine proteins, add $0.3 \mathrm{~mL}$ of NP-40 detergent and swirl gently (vigorous swirling introduces bubbles). For gels for urine proteins, add only two drops of NP-40 detergent and swirl gently. After addition of the detergent, carefully add the following:

Compound
\begin{tabular}{|l|c|}
\hline$\left(\mathrm{NH}_{4}\right)_{2} \mathrm{~S}_{2} \mathrm{O}_{8}(10 \%$ solution; recipe 6$)$ & Amount \\
\hline $\begin{array}{l}\mathrm{TEMED}\left(N, N, N^{\prime}, N^{\prime}-\right. \\
\text { tetramethylethylenediamine })\end{array}$ & $50 \mu \mathrm{L}$ \\
\hline
\end{tabular}

Ammonium sulfate $\left[\left(\mathrm{NH}_{4}\right)_{2} \mathrm{~S}_{2} \mathrm{O}_{8}\right]$ is a catalyst for the polymerization reaction, and TEMED is an accelerator. 
5. Pipette the acrylamide (approximately $15 \mathrm{~mL}$ ) into the trough. Very carefully layer 3-4 $\mathrm{mL}$ of double-distilled water over the acrylamide solution to bring the fluid level up to the very top.

6. Carefully lower the entire assembly into the bottom chamber of the ISO apparatus containing the appropriate volume of water. Allow the acrylamide to rise evenly by displacement in all tubes. Examine the tubes for bubbles. If there are any, use a 1-mL syringe with a cut-off yellow pipette tip attached (the wide top end cut off) to suck the acrylamide out of the top of the tube until the bubble is removed, and then let the fluid fall back to the proper level.

7. Allow the gels to polymerize for at least $2 \mathrm{~h}$.

The reproducibility of the first-dimension separation is essential for valid comparison of the final $2 \mathrm{DE}$ patterns. Therefore, it is wise to test several batches and blends of ampholyte to assure selection of the ampholyte that produces the best separation for each type of sample. (See Appendix D on ampholyte evaluation.)

\subsection{PREFOCUSING}

This step is to set up the $\mathrm{pH}$ gradient before the sample is introduced.

1. After the gels have polymerized for at least $3 \mathrm{~h}$, remove the entire assembly from the bottom chamber and remove the support stand from the upper buffer chamber and tubes. Empty the water from the bottom chamber and add either 200 or $300 \mathrm{~mL}$ (depending on which chamber is used) of $0.85 \% \mathrm{H}_{3} \mathrm{PO}_{4}$ (marked 10x); then add enough double-distilled water to fill the chamber to the full mark.

2. Carefully place the tube stand on its side and hold on to the sides of the metal retainer. Pull off the trough by wiggling it free of the polymerized acrylamide and retainer. Do not bend the metal retainer or stretch the gels in the tubes. Cut with a razor blade between the end of the tubes and the metal retainer. Remove the retainer and rinse the outside of the tubes. Place the excess acrylamide gel in the trash can and not in the sink; the gel is not soluble and will plug the plumbing. Reinsert the upper chamber with attached tubes into the lower chamber containing the acid solution.

3. The upper electrode solution is prepared by adding $200 \mathrm{~mL}$ of double-distilled water to a 600-mL lyophilizer flask and degassing with a vacuum pump or lyophilizer. The flask should be swirled to help free the air bubbles. To this water, add $0.4 \mathrm{~mL}$ of $10 \mathrm{~N}$ $\mathrm{NaOH}$ and pour the solution into the upper chamber. Remove the air bubbles which 
have formed between the top of the gel and the buffer from the upper electrode chamber. Using a $100-\mu \mathrm{L}$ Hamilton syringe containing the basic solution from the upper chamber, carefully dispense enough fluid to displace all the air that is in the tube. Be careful not to disturb the tops of the gels.

4. To mark the acidic end of the isofocusing gels, add approximately $5 \mu \mathrm{L}$ of a $10 \%$ SDS solution to the top of each ISO before prefocusing. The detergent will move down to the acid end of the gel and form a distinct "bulb," which will aid in distinguishing the acidic and basic ends of the gels.

5. Prefocus for $1 \mathrm{~h}$ at $200 \mathrm{~V}$ with the 7 -in. ISO setup ( $300 \mathrm{~V}$ for the 10 -in. ISO). About $10 \mathrm{~min}$ into the prefocus, check the tubes to be sure that there are no air bubbles. If there are air bubbles to remove, first turn off the power supply. Then remove the bubbles with a Hamilton syringe. (The lids are safety interlocked so that the power supply is disconnected from the banana plugs if the lid is removed.)

NOTE: Any DC power supply which delivers up to $1500 \mathrm{~V}$ at $10 \mathrm{~mA}$ will work for running ISOs (such as Glassman High Voltage, Inc., Series EH, or Power Designs, Inc., Model 2K20A).

\subsection{ISOELECTRIC FOCUSING}

\subsubsection{Nonradioactive Samples}

Load 5 to $30 \mu \mathrm{L}$ of sample containing $100-300 \mu \mathrm{g}$ (for Coomassie blue detection) or $20-50 \mu \mathrm{g}$ (for silver stain) of protein on each isoelectric focusing gel. A larger volume on the gel results in poor resolution and can cause the ISO gel to break.

Add the sample under the acid that is in contact with the gel. Do not push the syringe so hard that the sample will be forced out of the tube and back up into the upper buffer solution. Keep an accurate record of actual sample numbers (such as mouse liver \#1641, \#1642, \#1643, etc.) on a master protocol sheet (Figure 1): If creatine phosphokinase charge standards (see Appendix E, Procedure 1) are to be run with the samples, add approximately $2 \mu \mathrm{L}$ to each tube above the sample. These standards are useful position markers.

Although the optimal run time depends on the sample type, most cellular proteins are separated in the 7-in. ISO apparatus with a run time of approximately $14,000 \mathrm{~V} \cdot \mathrm{h}$; for example, run 
ISO-DALT DATA SHEET

EXPERIMENT NO.

DATE

INITIALS

DESCRIPTION:

ISO INFORMATION

Ampholyte Batch:

Start time:

Turn up:

Stop time:

Dalt Gel

Number
$\mathrm{pH}$ range:

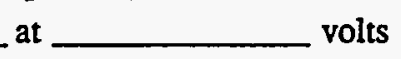

to

Total:

volts

volt-hours

\section{DALT INFORMATION}

Date Dalts run:

Run conditions:__ hrs at $\mathrm{mA}$

Protein detection:

ISO

Sample Identification

\begin{tabular}{||c|c|c|c|c||}
\hline & Sample & No. & Sample Identification & \\
\hline & & 1 & & \\
\hline & & 2 & & \\
\hline & & 3 & & \\
\hline & & 4 & & \\
\hline
\end{tabular}

\begin{tabular}{|l|l|l|l|l||}
\hline & & 5 & & \\
\hline & & 6 & & \\
\hline & & 7 & & \\
\hline
\end{tabular}

\begin{tabular}{|l|c|c|l|l||}
\hline & & 8 & & \\
\hline & & 9 & & \\
\hline & & 10 & & \\
\hline
\end{tabular}

\begin{tabular}{|l|l|l|l|l||}
\hline & 10 & & \\
\hline & & 11 & & \\
\hline & & 12 & $\cdots$ & \\
\hline & & 13 & & \\
\hline & & 14 & & \\
\hline & & 15 & & \\
\hline & & 16 & & \\
\hline & & 17 & & \\
\hline & & 18 & & \\
\hline & & 19 & & \\
\hline
\end{tabular}

Scanning Information: $\quad$ O.D. =

$\mathrm{x:}$

$y:$

i.c.r:

FIGURE 1 ISO-DALT Data Sheet 
for $17.5 \mathrm{~h}$ at $800 \mathrm{~V}$. Some samples, such as plasma or amniotic fluid, require approximately $12,000 \mathrm{~V} \cdot \mathrm{h}$. When using the 10 -in. ISO apparatus, the optimal run for tissue and cellular protein is $30,000 \mathrm{~V} \cdot \mathrm{h}$. Turn on the power supply to $1300 \mathrm{~V}$ for $23 \mathrm{~h}$ and $4 \mathrm{~min}$.

Any time a new type of sample is analyzed, it is advisable to determine the optimal running time by doing a time-course study.

\subsubsection{Radioactive Samples}

The isoelectric focusing apparatus (labeled clearly as to its possible contamination with radioactive materials, including the isotope in use) must be placed on absorbent plastic-backed paper. Samples (10- to $20-\mu \mathrm{L}$ aliquots containing 100,000 or more counts per minute, i.e., approximately $5 \%$ of the original isotope used) are applied to ISO gels using a Hamilton syringe labeled with "radioactive material" stickers or using disposable pipette tips that are discarded with the radioactive waste (accounting for less than $1 \%$ of the original isotope). The optimal run time depends on the sample type, as discussed above for nonradioactive samples.

After isoelectric focusing, the upper reservoir solution from radioactive gel runs $(200 \mathrm{~mL}$ of $0.1 \mathrm{M} \mathrm{NaOH}$ ) is decanted into a beaker and the lower reservoir solution (2 $\mathrm{L}$ of $10 \mathrm{mM}$ phosphoric acid) is left in the reservoir until monitored by Health Physics. Disposal is based on their analysis.

\subsection{NON-EQUILIBRIUM pH GRADIENT ELECTROPHORESIS (NEPHGE/BASO)}

Proteins with $\mathrm{pI}$ values higher than 9.0-9.5 do not enter isofocusing gels. To study such basic proteins, the technique of running a BASO gel under nonequilibrium conditions was devised by modifying the NEPHGE (non-equilibrium $\mathrm{pH}$ gradient electrophoresis) system (O'Farrell et al., 1977).

1. The BASO gels are cast in the 7-in. ISO apparatus using the same procedure as for ISOs (see Section 2.1, Casting Gels in the ISO Apparatus).

2. After the gels have polymerized, the lower tank reservoir is filled with $2 \mathrm{~L}$ of degassed $20 \mathrm{mM} \mathrm{NaOH}$ ( $4 \mathrm{~mL}$ of $10 \mathrm{~N} \mathrm{NaOH}$ diluted to $2000 \mathrm{~mL}$ ). The lower reservoir now contains the catholyte and the upper reservoir contains the anolyte, the reverse of the ISO system. The electrode wires are also hooked up in reverse (the black wire goes to the red electrode and the red wire goes to the black electrode). 
3. BASO gels are not prefocused. Apply samples with a Hamilton syringe directly to the upper gel surface in each tube (use about half the amount of protein needed to run an ISO gel). Overlay the samples with $4 \mathrm{M}$ urea, filling the remainder of the gel tube. Then, fill the upper reservoir with $200 \mathrm{~mL}$ of $10 \mathrm{mM} \mathrm{H}_{3} \mathrm{PO}_{4}\left(20 \mathrm{~mL}\right.$ of $0.85 \% \mathrm{H}_{3} \mathrm{PO}_{4}$, diluted to $200 \mathrm{~mL}$ ). The $4 \mathrm{M}$ urea cushion serves to protect the sample proteins from the acid in the upper reservoir.

4. To run the BASO gels in one day, start the electrophoresis at $400 \mathrm{~V}$ for $1 \mathrm{~h}$ and then turn up the power to $800 \mathrm{~V}$ for 4-8 $\mathrm{h}$ (for most samples), stopping the run at between 3000 and $8000 \mathrm{~V} \cdot h$. It is advisable to do a time study for each type of sample, because different samples require different run times to obtain optimal protein separation. The optimal run time for mouse and hamster liver samples is $6000 \mathrm{~V} \cdot \mathrm{h}$. A convenient overnight run can be done at $300 \mathrm{~V}$ for $20 \mathrm{~h}$. The basic proteins focus, but the more acidic proteins remain as streaks rather than spots.

\subsection{ACIDO ELECTROPHORESIS}

Urine contains a very acidic protein that always piles up at or goes off the left (acidic) end of an isoelectric focusing gel. This most acid urinary protein (MAUP) can be resolved by using an ACIDO run; $\alpha$-1-acid glycoprotein also runs nicely on an ACIDO gel. The conditions that differ from an ISO run will be specified here.

To make the gels for an ACDO first-dimension run, combine

Compound
\begin{tabular}{|l|c|}
\hline urea & Amount \\
\hline $\begin{array}{l}\text { acrylamide (30\% stock solution; } \\
\text { recipe 5) }\end{array}$ & $2.25 \mathrm{~g}$ \\
\hline ampholyte (pH 2.5-4) & $1 \mathrm{~mL}$ \\
\hline ampholyte (pH 3-10) & $0.3 \mathrm{~mL}$ \\
\hline water & $5.5 \mathrm{~mL}$ \\
\hline
\end{tabular}


Degas the solution and then add:

\begin{tabular}{|c|c|}
\hline Compound & Amount \\
\hline NP-40 & $0.3 \mathrm{~mL}$ \\
\hline$\left(\mathrm{NH}_{4}\right)_{2} \mathrm{~S}_{2} \mathrm{O}_{8}$ (10\% solution; recipe 6) & $90 \mu \mathrm{L}$ \\
\hline TEMED & $10 \mu \mathrm{L}$ \\
\hline
\end{tabular}

Cast the gels in a 7-in. ISO setup and allow the gels to polymerize for at least $2 \mathrm{~h}$. Prepare the lower chamber solution by mixing $3 \mathrm{~mL}$ of concentrated $\mathrm{H}_{2} \mathrm{SO}_{4}$ (sulfuric acid) and $2 \mathrm{~L}$ of water. Make the upper reservoir solution by degassing $40 \mathrm{~mL}$ of water and mixing it with $1 \mathrm{~mL}$ of the 3-10 ampholtye. Add this solution to the upper reservoir after the gels have polymerized. Debubble each tube carefully, as the top reservoir solution barely covers the tubes.

Prefocus the setup for $1 \mathrm{~h}$ as described in Section 2.2, Step 5. Then load approximately $20 \mu \mathrm{L}$ of sample and run for 3600-4000 V.h. Electrophoresis can be finished in one day using $700-800 \mathrm{~V}$ or it can be run at $200 \mathrm{~V}$ for $18-19 \mathrm{~h}$ overnight. After electrophoresis is complete, a stack of white material will be visible at the top of each gel. This material is protein that did not enter the gel and will wash out when the gels are unloaded. When the gels are unloaded into the equilibration buffer (recipe 7) containing bromophenol blue (an indicator dye), the liquid will change color to yellow or yellow-green. Rinse the gels until the equilibration dye stays blue. Run these ACIDO gels on normal DALT plates or use a $7-14 \%$ gradient to further spread out the highmolecular-weight proteins.

\subsection{ISO/BASO GEL RECOVERY AND EQUILIBRATION}

1. The gel recovery process is identical for the ISO and BASO systems. Rinsing the gels in equilibration buffer gets the gels ready for the second-dimension run in four ways: it rinses the ampholyte out of the ISO gel; it introduces SDS into the ISO gel; it changes the $\mathrm{pH}$ of the ISO gel; and it introduces tracking dye (bromophenol blue) into the gel. Take the dispenser of equilibration buffer (recipe 7) out of the refrigerator about two hours before it is time to unload the gels and stir it at room temperature. Number a set of 20 vials (5-mL glass screw-top). After making sure that the white SDS has gone back in solution, dispense $4-5 \mathrm{~mL}$ of the equilibration buffer into the vials.

2. Turn down the voltage, then turn off the power supply. Remove the safety lid and take out the ISO tube holder. For radioactive sample runs, see Section 2.3.2; for nonradioactive samples, drain the upper buffer solution into the sink and place the ISO tube holder on the unloading rack. Use a 1-mL syringe with a cut-off yellow tip filled 
with double-distilled water to expel the gels slowly into the numbered vials containing the equilibration buffer. If necessary, loosen the top of the gels by carefully moving the needle of an empty Hamilton syringe around the top edge. Decrease the water pressure as the gel moves down the ISO tube so the gel extrudes slowly into the collection vial.

3. Rock the vials gently in the buffer for approximately $5 \mathrm{~min}$. Then either apply the ISO gels to the DALT slabs immediately or freeze them at $-70^{\circ} \mathrm{C}$. It is important not to let the gels stay at room temperature for very long, because the proteins will diffuse out of them. To avoid this problem, freeze all gels and thaw them as needed on a consistent schedule. Frozen gels produce higher resolution spots than fresh gels, but they are thinner and somewhat more fragile. ISO gels may be frozen indefinitely at $-70^{\circ} \mathrm{C}$.

Those vials containing radioactively labeled proteins are stored at $-70^{\circ} \mathrm{C}$ in a rack labeled "Radioactive Materials" in a controlled area until the second-dimension run is done.

\subsection{CLEANING UP}

NOTE: To avoid generation of mixed waste, detergents such as Micro, RBS-35, or Isoclean ${ }^{\mathrm{TM}}$ should be used to clean the ISO tubes used with radioactive samples. However, superior results are only achieved using chromic acid, so after the ISO tubes are completely nonradioactive, they should be put in chromic acid cleaning solution overnight for a final cleaning.

1. If radioactive samples were separated in an ISO apparatus, the components of the apparatus are wiped with paper towels soaked in 50\% Count-Off ${ }^{\mathrm{TM}}$ (New England Nuclear, Boston, Massachusetts), followed by wiping with paper towels soaked in double-distilled water; the exception is the ISO tubes, which are soaked overnight in approximately $500 \mathrm{~mL}$ of a detergent solution. The paper towels and detergent solution (which account for less than $1 \%$ of the original isotope) are disposed of as low-level radioactive waste in appropriate containers. Health Physics must be asked to survey the ISO apparatus after cleaning to determine the level of remaining activity. The detergent solution (which contains less than $1 \%$ of the original isotope) is discarded in the liquid radioactive waste container. If nonradioactive samples were analyzed, the components of the ISO apparatus are simply rinsed with tap-distilled water and allowed to air-dry. 


\section{WARNING}

Chromic acid can cause severe burns to skin and eyes. Wear heavy rubber gloves, safety glasses, and a full face shield when using chromic acid solutions.

2. Except for tubes used in the analysis of radioactive samples, the glass ISO tubes are cleaned by soaking them overnight in a tank of room-temperature chromic acid cleaning solution (Fisher catalogue no. SC88-212). The tubes are permanently fixed in the acrylic frame. The level of acid must be adjusted so only the tubes and not the acrylic holder touch the acid. The chromic acid is stored in a round heavy glass container in which only the glass tubes are dipped (the acrylic would be destroyed by chromic acid). The chromic acid containers are kept in secondary containers in a designated hood.

3. The tubes (1.5 mm internal diameter) of the ISO assembly should be flushed by squirting distilled water into the tubes while they are positioned over a funnel so the rinse goes into a storage bottle. Chromic acid is a hazardous chemical and therefore must be discarded as hazardous waste. Do not rinse the acid off the ISO apparatus at the sink. After rinsing into a collection bottle, the ISO apparatus should be rinsed thoroughly in distilled water at the sink, and each tube should be flushed with doubledistilled water and then dried by air aspiration through the tubes. 


\section{THE DALT SYSTEM}

After first-dimension separation (ISO, BASO, or ACIDO), proteins are coated with the negatively charged detergent sodium dodecyl sulfate by equilibrating the gels in an SDS buffer. Then, in the second-dimension separation, the negatively charged proteins migrate different distances into a polyacrylamide gel based on their differences in size. The pore size of the gel varies from large at the top of the gel (low percentage of acrylamide) to small at the bottom (high percentage of acrylamide), so large proteins stay toward the top of the gel and smaller proteins migrate toward the bottom. For most of the work at this laboratory, a linear gradient of 10-17\% acrylamide is used, which produces separation of proteins with molecular weights of 10,000 to 200,000. Casting gels for the second-dimension electrophoresis requires planning and care, in order to pour 20 identical slab gel plates on which the ISOs will be loaded.

\subsection{CASTING DALT GELS}

NOTE: To ensure the reproducibility of the DALT system, use the same apparatus (boxes, tanks, etc.) for gels in a batch intended for comparison.

This laboratory has the option of using either a manual apparatus to pour 11 or 22 plates or a computer-assisted pouring apparatus to pour 23 plates. This manual describes both methods.

\subsubsection{Casting DALT Gels Manually}

Be sure that the entire gel casting system is clean, dry, and free of any polymerized acrylamide. Most polymerized acrylamide from a previous run will be blue if it is past the entry port for the underlay solution.

1. Place a bottom plate that has an angle cut at the edge in the bottom of the casting box with the angle up and to the left (toward the solution entry port).

2. Vertically stack either 11 or 22 plates into the gel casting box (depending on the box size) with the red strips to the right and vertical, interspersing three "bubble wrap" packing squares cut the same size as the plates between every fifth or sixth plate, and a teflon sheet for a spacer at the back of the box. Screw on the front cover of the box. 
3. Cut and place gel serial numbers (typed with carbon typing ribbon on \#1 filter paper) in order in front of the gel casting box.

4. Turn on the aspirator. Run the blue underlay solution (recipe 9) to the $T$ in the feed line and clamp with a hemostat. Shut off the vacuum line and make sure that the clamp to the line is closed. Be sure that the gradient-maker lines are clamped off, with one clamp on the heavy (18\%) line just as it leaves the gradient maker and the other on the main line just beyond the mixer. Set the gel casting chamber to a $45^{\circ}$ angle from vertical.

\section{WARNING}

Preparation of stock acrylamide solutions (which are carcinogenic and neurotoxic) from crystalline chemicals must be done in the Carcinogen Laboratory. The working solution must be clearly labeled "DANGER: CANCER HAZARD" and be transported with secondary containment from the Carcinogen Lab to the laboratory where it is used. All personnel working with acrylamide must take the course on "Safe Handling of Carcinogens."

NOTE: There will be about $15 \mathrm{~min}$ available to pour the plates between the addition of the ammonium persulfate and TEMED and when the gels begin to polymerize - so work fast!

5. Make the appropriate acrylamide working solutions (a $9 \%$ solution and an $18 \%$ solution) from the stock mixes (recipes $6,10,11$, and 12) according to the following table.

\begin{tabular}{|c|c|c|c|c|c|}
\hline $\begin{array}{c}\text { crylamide/bis }{ }^{\mathrm{a}} \\
(\mathrm{mL})\end{array}$ & $\begin{array}{l}\text { Buffer } \\
\mathrm{L} 10^{\mathrm{b}} \\
\text { (mL) }\end{array}$ & $\begin{array}{l}\text { Buffer } \\
\text { L20c } \\
(\mathrm{mL})\end{array}$ & $\begin{array}{c}10 \% \text { SDS } \\
(\mathrm{mL})\end{array}$ & $\begin{array}{c}10 \% \\
\left(\mathrm{NH}_{4}\right)_{2} \mathrm{~S}_{2} \mathrm{O}_{8}{ }^{\mathrm{d}} \\
(\mathrm{mL})\end{array}$ & $\begin{array}{c}\text { TEMED } \\
(\mu \mathrm{L})\end{array}$ \\
\hline
\end{tabular}

For 11 plates:

9\% solution

$18 \%$ solution

$\begin{array}{rrr}80 & 160 & - \\ 240 & - & 120\end{array}$

$\overline{120}$

2.4

3.6

4 70

For 22 plates:

$9 \%$ solution

192

$384+2$

$18 \%$ solution

440

384

-

5.7

6.6

220

2

10

${ }^{\mathrm{a}} 27 \%$ Acrylamide/0.8\% bis (recipe 10).

${ }^{b}$ Recipe 11 .

c Recipe 12.

d Ammonium persulfate (recipe 6). 
Degas the solution after mixing the acrylamide and buffer L10 or L20. Add the SDS, and then swirl the container gently while adding the ammonium persulfate and TEMED. The amounts of persulfate and TEMED required may vary slightly with different brands of reagents or the temperature of the laboratory.

6. Pour all the light (9\%) solution into the right side of the gradient maker. Open the line beyond the mixer to fill the tubes and mixer up to the gel casting box so that the light solution level is at about the " 27 " mark for 22 plates or the " 21 " mark for 11 plates. Add the heavy (18\%) solution to just below the 27 mark, taking care not to overfill (the foam settles down to liquid). Not quite all of the $18 \%$ solution will be used. Bleed the air bubbles out of the line.

- 7. Remove the clamp on the $18 \%$ line and the clamp above the mixer to allow the solution to run into the "funnel" formed by the $V$ in the casting box. Watch the level in the casting box and slowly rotate the box to vertical as filling is completed. Then begin adding ID number tags (Appendix E, procedure 2) quickly into each gel. Use a level to make sure the plates in the box are completely even.

8. Clamp the line between the vacuum and blue sucrose underlay inlets. Open the line for the blue underlay solution.

9. While the underlay solution is flowing in, open the vacuum line, being sure that the water suction is on. Add water to both chambers of the gradient maker, flushing about $2 \mathrm{~L}$ through the system at this stage.

10. While the underlay solution is reaching the appropriate level (i.e., almost to the bottom of the glass plates), continue dropping the numbers in the right side of each plate, and make sure the numbers fall through the liquid to the bottom corner of each gel. Then immediately (and very gently) overlay approximately $1 \mathrm{~mL}$ of water-saturated secbutanol (recipe 13) or Photoflo solution (recipe 14) onto each gel. Photoflo is less hazardous than the alcohol.

11. Adjust the underlay solution container up or down so that the blue level remains just below the bottom of the plates without having to clamp the line. This placement allows slightly more displacing fluid to be drawn in as the gels polymerize.

12. Cover the box with plastic wrap so the tops of the gels do not dry out or get dirty. Flush two more liters of water through the gradient maker and tubing. Drain the system and then drain the mechanical mixer by inverting it (the outlet tubes are at the top of the mixer). 
Allow the gels to polymerize for at least $2 \mathrm{~h}$. It is important for the polymerization to proceed from the top down, or the plates will contain swirls or lines.

13. After the gels have polymerized, carefully disassemble the apparatus using a single-edge razor blade to separate each plate. Wash the plates carefully with warm water, and remove excess acrylamide from the sides and edges of the plates. Rinse the top surface of the gel with tap-distilled water, and stack the plates in a dish rack sideways (with the rubber hinges up) to drain excess water away from the surface of the gel. Examine the gels for air spaces and discard any that contain air bubbles (which look like tree branches). If the gels are all good, flush the tops of the extra gels with buffer L (recipe 15) diluted 1:4, wrap them in plastic wrap and foil, and put them in the refrigerator for future use. The stored gels can be used for about a month for Coomassie-blue staining results if they are kept moist, wrapped well, and stored cold.

\subsubsection{Casting DALT Gels with Computer Assistance (Angelique)}

\subsubsection{System Operation}

Angelique, designed at Argonne by Leigh Anderson and Bill Eisler, comprises a pair of four-channel peristaltic pumps controlled by a minicomputer (a DEC Falcon, which is a micro version of the PDP-11). Each pump delivers acrylamide, buffer, TEMED, and ammonium persulfate in constant proportions. The "light" pump delivers a mixture appropriate for the top (low-percentage acrylamide) end of a gradient SDS slab gel, while the "heavy" pump delivers the bottom (highpercentage acrylamide) solution. Generally these solutions are about $10 \%$ (light) and $17 \%$ (heavy) acrylamide. These percentages (and those referred to by the program) refer to the final concentration of acrylamide at the output of the pump, not the acrylamide stock solutions. The pumps are configured to deliver three parts acrylamide solution to one part other (buffer, TEMED, or ammonium persulfate).

The pumps are driven by stepping motors, which move in small, programmed increments (200 steps per revolution). The computer controls these motors by sending electronic pulses to them through power amplifiers. Since each step (1/200 revolution of the pump) has a fixed volume, the total volume of the gradient can be expressed as the number of steps which must be pumped to deliver the necessary liquid to the casting box. About 105,000 steps are required to fill a $7 \times 7$-in. box, and 175,000 steps to fill an $8 \times 10$-in. box.

The output of the pumps is combined in the following way: light and heavy acrylamide solutions are combined and delivered to the mixing chamber, while the other six lines (light and heavy buffer, and two each for TEMED and ammonium persulfate) are also combined and then 
delivered to the mixing chamber. This scheme ensures that the ammonium persulfate and TEMED contact the acrylamide only at the mixing chamber (which can be flushed out). Each pump delivers the amount of TEMED and ammonium persulfate necessary to cause slow polymerization of its own concentration of acrylamide, and therefore the amount of these chemicals varies smoothly according to the acrylamide concentration down the gradient.

The output of the mixing chamber is fed by a tube to the casting box to be filled. The end of the feed tube is a plastic 2-mL pipette with a short piece of rubber tubing on the end, which fits snugly into the opening in the sucrose side chamber. When in position, the feed tube causes the gradient material to be pumped directly into the casting box. The sucrose chamber surrounding the feed tube is filled to the correct height (marked on box) with sucrose so that when the tube is withdrawn after the gradient is pumped, the heavy sucrose follows the gradient down the passage into the box, thereby pushing the acrylamide into the box so it will not polymerize in the tubing leading to the box.

The pumps are controlled by the computer through the Angelique program. This Pascal program allows either direct control of the pumps (for pumping a given number of steps of either light or heavy solution) or the specification of a gradient which is then computed in real time to determine how many pulses to send to each pump over the course of the gradient. In case of emergency (acrylamide leaking out or a major mistake of some kind), the pumps may be stopped by turning off power to the pump power supplies - the switch marked "Stepping Motor Main Power" at the back of the bottom black shelf to the right of the casting bench — or by hitting the red "DC POWER" switch on the control box that controls the program.

A pair of platinum wires is used to sense when the level of liquid in the casting box reaches the desired height. If the "full" option is selected (instead of the "constant" volume option), the pumps will continue to deliver, once the gradient is finished, whatever percentage acrylamide was specified for the bottom of the gradient until the liquid reaches the level of the sensor. This procedure allows gels of constant height (run-to-run) to be made even though the casting boxes differ slightly in volume (and thus in the height corresponding to a fixed volume of gradient). It is good practice to use the same casting box for pouring gels that are to be scanned and compared.

An overlay of $0.1 \%$ Photoflo in Angel's buffer (recipe 16) is applied to all the gels simultaneously by a 23 -channel peristaltic pump (because the box holds 23 plates) following the pumping of the gradient. Pump enough overlay to cover the surface of the gel (about $1 \mathrm{~min}$ of pumping). Following overlay pumping, the overlay feed tubes should be removed immediately to avoid disturbing the polymerizing gradients.

Recently, several companies have begun selling a liquid, pre-mixed formulation of acrylamide and bis (37.5:1 ratio), so it is no longer necessary to deal with the hazards of large amounts of crystalline acrylamide. Liquid acrylamide from Amresco (Solon, Ohio; catalogue 
no. P0025443) and BioRad (Hercules, California; catalogue no. 161-0149) are being used with equally good results.

\subsubsection{Casting DALT Gels}

On the day prior to casting DALTs:

1. Take a bottle of overlay solution (recipe 16) and Angel's buffer solution (recipe 17) out of the refrigerator. Check that there are sufficient amounts of both solutions, and warm them to room temperature. Prepare fresh light (12\%; recipe 18) and heavy (22.46\%; recipe 19) acrylamide solutions, making $1 \mathrm{~L}$ of each solution for each box poured. Better results are obtained by using fresh acrylamide solutions, especially when the gels will be silver-stained.

2. Take a bottle of sucrose underlay solution (recipe 9) out of the $-20^{\circ} \mathrm{C}$ freezer to thaw.

3. Load clean, dry plates into the casting boxes ( 6 plates, 1 bubble sheet, 6 plates, 1 bubble sheet, 5 plates, 1 bubble sheet, 6 plates) with the rubber hinges to the left. Put the face plate on, but do not tighten the screws. Wedge the notched teflon spacer at the back of the box, with the notch located toward the pouring apparatus, so that there is room for the overlay tubes to fit during the casting operation. Drop ID number tags into the plates near the red rubber hinges so that the print faces the teflon spacer. Cover the top of the box with plastic wrap to keep out dust.

On the day for casting DALTs:

4. On the morning DALTs are to be cast, take the $10 \%$ ammonium persulfate and TEMED out of the refrigerator. Prepare fresh ammonium persulfate (recipe 20) and TEMED (recipe 21) as needed. One box requires $50 \mathrm{~mL}$ each of TEMED and persulfate. If there is leftover stock persulfate, pour it in the large waste beaker to help polymerize the waste acrylamide solution.

\section{CAUTION}

Do not use glass bottles, an alternative pump, or other types of caps for the evacuation step.

5. Degas the Angel's buffer solution and then the light and heavy acrylamide solutions using the designated vacuum pump (labeled "FOR DEGASSING ACRYLAMIDE 
SOLUTIONS ONLY"). The pump is equipped with a small trap in the line to catch any acrylamide solution that may be sucked into the tubing. Check the trap frequently; normally nothing should be sucked into the trap.

The solutions should be in Nalgene ${ }^{\circledR} \# 2026-4000$ bottles with evacuation caps. Connect each bottle to the vacuum pump by screwing on the designated lid connected to the pump by Tygon ${ }^{\circledR}$ tubing, and turn on the switch. The regulator has been preset to $15-20 \mathrm{~mm} \mathrm{Hg}$, and these polypropylene bottles are approved for use with this vacuum. Degas the solutions for approximately $5 \mathrm{~min}$ each. Then turn off the vacuum pump, disconnect the vacuum hose, and unscrew the cap. In case of an equipment malfunction or a contained acrylamide spill, notify your supervisor immediately for further instructions. If personal contamination or an uncontained spill occurs, dial 911 and request assistance.

6. While solutions are degassing,

a. Turn on the pump power supply, which is controlled by a small switch box labeled "Stepping Motor Main Power" at the back of the bottom black shelf on the right-hand side of the bench. When the switch is turned on, fans will start running. This is the control switch that will shut down the entire pouring operation in case of an emergency.

b. Turn on the switch on the gray panel mounted next to the vacuum chamber, which will give power to the magnetic mixer under the gradient mixing chamber, the peristaltic pump used for overlay, and the vacuum pump.

c. Turn on the level detector, which is a small grey box on the shelf above the left side of the bench, by flipping the small main power switch mounted at the bottom of the front face of this box. The main power light will come on. Do not touch any other switches on this box!

d. Turn on the red "DC power" button on the lower right corner of the computer control box (on the shelf above the computer terminal).

7. Prime the overlay solution by engaging the pressure plate of the multi-channel peristaltic pump, setting the overlay bottle on top of the pressure plate, connecting the side arm of the bottle to the intake tube, and turning on the switch. Fill the 23 overlay tubes and allow them to drip slightly into a tray sitting on top of the box of plates, and then turn off the switch. Remove the tray and insert the tubes at the top of the 23 plates. 
8. Prime the stepping pump lines by doing the following:

a. Prime the Angel's buffer line first (only Angel's buffer is connected at this time) while the next solution (heavy acrylamide) is being degassed. Screw the appropriate cap on the bottle, and make sure the waste flask stopper is in place. Turn on the Angelique vacuum pump on the platform. With the waste port (the side tube on the magnetic mixer that leads to the vacuum trap) open (as it should be from the previous run's cleanup), pump 28,000 steps of light solution through the system by typing $\mathrm{L} 28000$ at the computer terminal).

b. Tighten the TEMED tubing lines around the MasterFlex pump heads, and clamp the pumps shut. Connect the ammonium persulfate, TEMED, and degassed acrylamide solutions to their appropriate feed lines on Angelique. All tubes should be labeled so they will be inserted into the proper bottle; check all lines to ensure they are oriented to feed in from the left and pump out to the right. Light solutions are then connected to the pump on the right; heavy solutions are connected to the pump on the left. Fill the 1-L beaker (dedicated for acrylamide use only) with distilled water. Close the damper with both the clamp and a hemostat.

c. Prime the heavy pumps by typing $\mathrm{H} 10000$ at the terminal, and then check to see that all four solutions are flowing (particularly the TEMED, as it tends to clog up the pump tubing) and that all air bubbles are moving along in the tubing. Repeat with 10,000 steps of light solutions (type L10000). Always end the priming cycle with light solutions, so that the beginning of the gradient is always light. Check that there are no bubbles in the tubes. Turn off the vacuum pump and close the clamp on the waste line.

9. Prepare the DALT box for casting:

a. With your fingers, tighten the screws on all casting boxes, checking to see that the sealing gasket made of small Tygon ${ }^{\circledR}$ tubing is in the proper track and is not being crushed when the lid is tightened; otherwise, leaks will result.

b. Insert the gradient feed tube into the sucrose chamber. A liquid-tight seal is required here, made by forcing the tapered feed tube (a 2-mL pipette) covered with rubber tubing into a tapered hole in the sucrose chamber. Load the sucrose chamber with sucrose underlay to the mark on the chamber (premeasured to deliver the correct amount of sucrose). 
c. Insert and tape the level detector probe along the left side of the pouring box, and make sure that the red "high limit" light on the upper right-hand side of the sensor power source is not on; if it is, the sensors are touching and must be separated.

d. Check that the vacuum (waste) line is clamped.

10. Cast the DALT gels. At the terminal:

1. Type $\mathrm{C7}$ and press return. $\quad(\mathrm{C}=$ cast $)$

2. Type 9 . and press return. (\% acrylamide of light solution)

3. Type 17. and press return. (\% acrylamide of heavy solution)

4. Type 2 and press return. (number of points in the gradient)

5. Type 10. and press return. (starting value of gradient variable)

6. Type 17. and press return. (percentage of acrylamide at final concentration)

7. Press return.

8. Type 105000 and press return. (number of pulses to fill the $7 \times 7$-in. box)

9. Type 0 and press return. (length of delay desired; $0=$ no delay; typing an integer will delay by that number of pulses.)

10. Type $f$ and press return. $\quad(f=$ full; $c=$ constant; the full option allows the box to fill until the solution contacts the level-detection wires; the constant option delivers the given number of pulses.)

11. Press return.

12. Press return. (Note: Steps 11-17 are a checklist to

13. Press return. ensure that appropriate preliminary

14. Press return. steps were completed as described

15. Press return. above. It is useful to read the

16. Press return. questions and verify the steps.)

17. Press return. 
The stepping pumps should start at this point and continue until the box is filled to the proper height (according to the position of the sensor). In general, use the "FULL" option in order to get gels of a reproducible height in the slightly different boxes. Double-check to make sure that no tubing is kinked, especially the heavy feed line of acrylamide.

11. After a box is filled (according to the sensor):

a. Remove the gradient feed tube from the sucrose chamber and place it in the beaker of water. Check that sucrose is entering the box.

b. Unclamp the vacuum waste line and turn on the vacuum pump, allowing about $50 \mathrm{~mL}$ of water through the feed line; this clears the line of polymerizing acrylamide. Remove the feed line from the water and let the vacuum suck all the water from the feed line.

NOTE: Overlay must be applied immediately or the tops of the gels will be disturbed.

c. Turn on the overlay pump (peristaltic pump) for about a minute or until the overlay solution covers the tops of the gels; turn the peristaltic pump off and remove the overlay tubes from the plates.

d. Remove the level sensor from the box. Cover the box with plastic wrap and allow the box to sit undisturbed for at least $4 \mathrm{~h}$ until fully polymerized.

12. Prepare for the next box:

a. Type $\mathrm{4} 4000$ (to flush the lines with light solutions).

b. Push the cart carrying the overlay pump and solution lines along the lab bench until the overlay feed lines will reach the next box. Be careful not to disturb the box which was just poured.

c. Close the vacuum waste line, tighten the screws on the box, and insert the overlay tubes into the top of the plates in the new box.

d. Insert the feed tube into the sucrose chamber and add sucrose to the indicated line. Insert the level sensor.

e. Repeat steps 10 ("Cast the DALT gels") and 11 ("After a box is filled"). 


\section{Cleanup and shutdown}

a. Disconnect all solutions from the stepping and peristaltic pumps. First, remove the tubes from the TEMED and persulfate bottles, and pour these solutions in the dedicated plastic waste beaker on the bench. Put the tubing in the 1-L beaker of water which will be used for rinsing all tubing.

b. Set a tray on top of the covered box of plates that was just poured, and put the 23 overlay lines into the tray. Clamp the tubing, and disconnect and cover the bottle of overlay solution. Tip the bottle on its side and open the clamp so that the overlay solution in the line drains back into the bottle. Pump the lines empty, pump water through them, and finally pump the lines empty again. Turn the peristaltic pump off and release the pressure plate on the tubes.

c. Turn the level sensor off, pull the sensor wire out of the casting box, and put it in the secondary tray wrapped in a paper towel.

d. Take the lid off the buffer bottle; let the fluid in the attached pipette drain down into the buffer bottle, and put the pipette in the 1-L beaker of water, propping it against the peristaltic pump shelf. Then remove the lid from the heavy acrylamide and put the pipette line into the water. Pump water through all heavy lines by typing H30000. Make sure that the water gets primed through the buffer line. Remove the heavy acrylamide line from the beaker, let it drain, and store the line, wrapped in a paper towel, on the secondary tray. Put the remainder of the heavy acrylamide into the plastic waste beaker on the bench.

e. Remove the lid from the light acrylamide bottle, and put the pipette in the attached beaker of water, making sure that there is enough water in the beaker for rinsing. Pump water through all light lines by typing L 30000 at the computer terminal. Watch the fluid in the waste flask to ensure it does not overflow into the vacuum pump. Under normal pouring conditions, there should be plenty of room left in the vacuum flask. Remove the light acrylamide line from the beaker, let it drain, and put it on the secondary tray. Repeat for the buffer line. Remove the TEMED and persulfate lines also. Put the remaining light acrylamide into the plastic waste beaker.

f. Open the damper by removing the hemostat and opening the clamp. Pump all tubing empty (by typing H15000 and then L15000 at the terminal). 
g. Empty the waste flask into the plastic waste beaker on the bench. Rinse the flask with the water remaining in the 1-L rinse beaker and add this water rinse to the waste beaker. Reattach the flask to Angelique.

h. Add approximately $400 \mu \mathrm{L}$ of TEMED and 3-5 $\mathrm{mL}$ of ammonium persulfate to the liquid acrylamide waste. Allow the acrylamide solution in the waste beaker to polymerize for several hours and then dispose of it as general (non-hazardous) solid waste. In the event that the waste does not polymerize (because too much water rinse was used), pour the liquid (usually quite viscous) into the liquid waste bottle, and enter the amount in the waste log.

i . Turn off the computer control box by pushing the red "DC power" button, and the button will pop up.

j. Turn off the pump power supplies (controlling the stepping pumps) by flipping the switch on the right side of the bench under the bottom black shelf.

k. Loosen the TEMED tubing from the MasterFlex pump head by unscrewing the plastic screw and physically loosening the tubing so it is not kinked but is loosely curved, and unclamp the MasterFlex pump.

1. Store bottles of solutions at $4{ }^{\circ} \mathrm{C}$, and rinse the acrylamide, TEMED, and persulfate bottles. Put any extra sucrose underlay solution back in the $-20^{\circ} \mathrm{C}$ freezer.

\subsection{ADDITION OF A STACKING GEL}

Most of the time a stacking gel is not necessary because the ISO gel acts as its own stacker. However, on rare occasions, such as when running Cleveland gels, a stacker might be desired on top of the slab gel. If so, proceed through the following four steps.

1. After the slab gels have polymerized, rinse the tops of the plates with buffer $L$ (recipe 15) diluted 1:4 or with $16 \mathrm{~mL}$ of Angel's buffer (recipe 17) diluted to $100 \mathrm{~mL}$. Pour the buffer off and put the plates sideways in a dish rack to drain. 
2. For 10 plates, combine

\begin{tabular}{|c|c|}
\hline Compound & Amount \\
\hline stacking gel mix (recipe 22 ) & $40 \mathrm{~mL}$ \\
\hline $\begin{array}{l}\text { ammonium persulfate, } 10 \% \text { solution } \\
\text { (recipe 6) }\end{array}$ & $800 \mu \mathrm{L}$ \\
\hline TEMED & $30 \mu \mathrm{L}$ \\
\hline
\end{tabular}

Add $3 \mathrm{~mL}$ of this solution to each plate. (For 20 plates, double the stacking gel mix and ammonium persulfate, but use only $50 \mu \mathrm{L}$ of TEMED.)

3. Gently overlay $1 \mathrm{~mL}$ of water-saturated sec-butanol (recipe 13 ) or $0.1 \%$ Photoflo (recipe 14 or 16) on each gel.

4. Allow 20-30 min for polymerization. Pour off the overlay and proceed to load the plates as soon as possible, because the polymerized acrylamide tends to pull away from the glass plates when allowed to dry out, and air pockets form at the bottom of the gels.

\subsection{LOADING ISO GELS ONTO DALT GELS}

1. If the ISO gels are frozen, they should be moved from the $-70^{\circ} \mathrm{C}$ freezer to a $-20^{\circ} \mathrm{C}$ freezer about an hour before they are to be loaded.

NOTE: During loading, thaw out only 3 or 4 vials at a time in a beaker of warm water, so the gels will not sit at room temperature and begin to swell and stretch. Stretched gels cannot be loaded uniformly, and protein resolution is severely affected. 


\section{CAUTION}

Radioactive ISO gels (containing approximately $90 \%$ of the protein-bound isotope loaded onto the gel, which is about $4 \%$ of the original isotope used) are loaded onto the top of the DALT gels in the controlled area. The loading platform should be labeled "RADIOACTIVE MATERIALS" and placed on top of a piece of plastic-backed absorbent paper. The buffer used for equilibration (containing about $10 \%$ of the protein-bound radioactivity, which is less than $1 \%$ of the original isotope) is poured into a liquid radioactive waste container. The glass vials and plastic caps are discarded in solid radioactive waste containers. The beaker into which the equilibration buffer was decanted is wiped dry with tissues, which are discarded as solid radioactive waste (accounting for less than $1 \%$ of the original isotope).

2. Pour the first ISO gel and equilibration buffer onto a plastic tea strainer, letting excess equilibration fluid drain into a beaker. Equilibration buffer containing dithiothreitol or 2-mercaptoethanol must be collected and disposed of as hazardous chemical waste. Equilibration buffer without either of those components may be discarded down the drain. To rinse off the excess equilibration buffer, squirt the ISO gel with buffer $\mathrm{L}$ diluted 1:4 if the plates are cast by hand, or with Angel's buffer $(16 \mathrm{~mL}$ diluted to $100 \mathrm{~mL}$ ) for computer-poured plates. Pour out the ISO gel onto the top of the loading platform, and position the gel so that the enlarged SDS bulb is at the left (acidic) side. There will not be a bulb if the samples were prepared in urea and if SDS was not added during prefocusing. In this case, orient the ISO gel with the razor rough-cut end to the left (acidic) side and the smooth tapered end to the right (basic) side.

BASO gels are extruded the same way as ISOs, but they are loaded on the DALT gels "backwards," with the jagged basic end to the right and the smooth acidic tapered end (sometimes showing a dyed dot of proteins which did not enter the gel) to the left. This orientation will facilitate the preparation of a composite map at the end of an ISO and BASO run by matching the overlapping spots that are common to both patterns.

3. Place the DALT gel plate on the front of the lectern with the red rubber strip to the right and the label in the lower right corner. Add a few drops of the diluted Angel's buffer from a squirt bottle onto the top of the DALT gel and then roll the ISO gel onto the top of the DALT gel. Smooth the ISO gel into position with a spatula, eliminating any air bubbles underneath it. Turn the DALT plate upside down on a towel to drain off any excess fluid.

4. Record the DALT gel numbers on the sample protocol sheet. 


\section{WARNING}

- Be sure the cap of the agarose flask is loose or off during microwaving.

- Agarose solutions often superheat when they are microwaved, boiling over when disturbed, e.g., when a pipette is introduced, and serious injury can result. Use extreme caution when handling heated agarose. Direct the flask away from you when starting to use the solution.

5. Overlay each gel with approximately $0.5 \mathrm{~mL}$ of melted agarose running buffer (recipe 23). (The agarose is stored in the freezer in $100-\mathrm{mL}$ portions and can be liquified in the microwave oven.)

Remove any bubbles that form in the agarose on the DALT gels. Allow the agarose to solidify before loading plates in the DALT tank. The plates are run sideways in the tank, so the agarose must hold the ISO gel firmly against the slab gel.

6. In some cases, molecular weight standards may be useful to run on the DALT gels. Molecular weight standards can be purchased from several companies, such as BioRad or Pharmacia. Standards can also be prepared in the laboratory from rabbit muscle or rat heart (Appendix E, procedure 3).

\subsection{RUNNING THE DALT ELECTROPHORESIS SYSTEM}

\section{CAUTION}

Plates with radioactively labeled ISOs are run in a tank in a controlled area.

The DALT tank in which the slab gels are run contains $33 \mathrm{~L}$ of the DALT buffer and must be labeled "RADIOACTIVE MATERIALS."

Each set of DALT gels must be run in a clean tank with fresh buffer. Never reuse the buffer. Prepare the buffer in the DALT tank early in the morning (or the previous day) so the buffer can be thoroughly chilled (to about $4{ }^{\circ} \mathrm{C}$ ) prior to use. The 20 -gel tank contains $26 \mathrm{~L}$ of DALT buffer (recipe 24).

1. Prepare the buffer solution by weighing out the components and mixing them on a stirring plate in approximately $4 \mathrm{~L}$ of water. Meanwhile, fill the tank with water and turn on the circulation pump to rinse out the last bit of old tank buffer. Be sure to bleed any air out of the line to avoid damage to the water-primed circulating pump motor. Pump the rinse water out of the tank and begin refilling the tank with water. Add the 
concentrated buffer solution from the beaker, and fill the tank to the 26-L fill mark. Put the plate spacers back in the tank after the buffer is chilled, just before the DALT gels are to be run.

\section{CAUTION}

DALT plates wet with buffer are slippery.

2. Insert the DALT plates carefully into the rubber tank spacers with the ISO gel (blue sample) along the left side and with the red rubber hinge along the bottom, using a slight leftwise sliding motion so that the tank gasket flaps open to the left. Slide the plates firmly to the bottom. Dipping the plates in the tank buffer first will help them to slide into place.

After the plates are in position, the buffer level should be even with the spacers of the plate and not above the top of the plates; otherwise, there will be an electrical short circuit.

3. Close the lid on the tank. Attach the electrodes to make proper contact with the power supply. Next, turn on the power supply and run the system until the blue tracking dye runs off the bottom of the DALT gel. The best resolution of protein spots is achieved when the voltage and the current are both limited (to $150 \mathrm{~V}$ and $0.6 \mathrm{~A}$, respectively) for a convenient overnight run of about $16 \mathrm{~h}$. These conditions minimize heat generation in the DAIT gels.

4. When the run is finished the next morning, turn off the power supply by shutting down the main line voltage switch. If the same low-voltage run is used repeatedly by the same person, it is possible to simply turn on or off the main line switch to the power supply so the setting remains absolutely constant for subsequent runs. Make sure the voltage setting is off or low before turning on the power supply for a high-voltage run to avoid large power surges; after the power supply is on, set it to the high voltage desired.

\section{CAUTION}

DALT plates wet with buffer are slippery.

5. Carefully remove the DALT plates from the tank one at a time and put them in a dish rack to carry them to the sink. Rinse the plates with water. Place the plates one at a 
time on the unloading lectern and pry them open with a screwdriver or a DALT opener tool. Wear gloves when handling the gels, to avoid getting fingerprints on the gel.

6. Use a razor blade to free the gel. along the spacers and to free the ISO gel from the DALT gel.

7. Peel the gel from the glass carefully and place it in the Coomassie blue stain solution (recipe 25), in the silver-stain fixing solution (see Section 4.2), or in transfer buffer (see Section 6.1). In case the gel rips, remove the ripped section last and work toward the rip, so the rip does not get worse.

8. Place the box of gels ( 10 per box for Coomassie blue, four per box for silver stain) on the shaker for staining or proceed with the protein transfer procedure.

\subsection{CLEANING THE DALT PLATES}

Soak the used plates in distilled water with a small amount of SDS in the bucket. When cleaning, go over all surfaces (including the edges) with a teflon scrubber. Finally, rinse the plates with water (and possibly ethanol) and air-dry them in the open position in a drying rack, or stand them on a clean surface in an inverted vee $(\Lambda)$ configuration. Try not to open the plate books past a right angle or the bindings might break. Store the dry, clean plates in an enclosed cabinet or covered in the casting box to keep them free from dust.

\subsection{DRAINING THE DALT TANKS}

DALT tanks are emptied immediately after use by pumping the buffer down the laboratory drain, except when radioactive samples have been used. Tanks are then rinsed with distilled water, drained, and left to dry until the next use. This procedure minimizes bacterial growth in the tanks, which causes the appearance of horizontal streaks in stained gels.

After running radioactive samples, the tank buffer must be analyzed by Health Physics and, if contamination is detected, the buffer must be siphoned into a liquid radioactive waste container. The total activity discarded is based on the Health Physics analysis of the buffer. 


\section{PROTEIN DETECTION METHODS}

\subsection{STAINING WITH COOMASSIE BLUE}

1. Put 10 gels into $1 \mathrm{~L}$ of Coomassie blue stain (recipe 25). Avoid using an acetic acid/ethanol stain because of the instability of the mix and the volatility of the fumes. Shake the gels in the stain for at least $6 \mathrm{~h}$ (overnight runs work well) on a reciprocal shaker. Because the Coomassie stain is made in approximately 50\% ethanol and $2 \%$ phosphoric acid, it must be disposed of as a liquid hazardous waste (acidic $\mathrm{pH}$ and the flammability of the ethanol).

2. To destain the gels, shake them in five washes of $20 \%$ ethanol for at least $1 \mathrm{~h}$ each, and leave the gels in the last wash overnight. The destaining solution may be poured down the drain.

3. Prior to scanning or photography, shake the gels for $1 \mathrm{~h}$ in distilled water. Wipe off any stain residue from both surfaces of each gel with a gloved hand before scanning.

4. Scan with the Eikonix 1412 scanner using a green filter (Wratten \#58).

\subsection{STAINING WITH SILVER}

The method presented below is a modification of the technique described by Guevara et al. (1982).

\subsubsection{Hints for Silver Staining}

- The best results are obtained if gels are stained directly with silver. Gels previously stained with Coomassie blue can be subsequently silver-stained, but the backgrounds will be darker than usual.

- All water must be double-distilled; the use of tap-distilled water will produce a cloudy background.

- Only fresh chemicals and solutions should be used. Using small bottles, prepare aliquots of ammonium hydroxide and formaldehyde from the larger stock bottles, because the chemicals are volatile and their concentrations will remain more stable. 
- Use a plastic mallet the same size as the gels for holding the gels in place when draining off solutions so the gels are not touched by fingers. Place as little pressure as possible against the mallet while retaining the gels, and perform this manipulation quickly. If excessive pressure is used or if the surface of the gel is allowed to dry in the air, the result will be large staining artifacts in the gel.

\subsubsection{Silver Stain Protocol}

\section{CAUTION}

- Ninety-five percent ethanol is flammable and must be stored in the original containers in appropriate flameproof cabinets. The dilute ethanol solutions (50\% and $20 \%$ dilutions of $95 \%$ ethanol) required for the silver-stain protocol should be prepared at least a day in advance of use so that the solutions have a chance to equilibrate to room temperature. The solutions are stored in labeled Nalgene carboys in the laboratory where they will be used.

- Never use absolute alcohol for making stain, destain, or silver-stain solutions, because there is a chemical used in making $100 \%$ alcohol which interferes with the silver-stain chemistry. Use only $95 \%$ ethanol; thus when referring to " $50 \%$ ethanol," it is in fact $47.5 \%$ ethanol.

- Formaldehyde is volatile, flammable, and carcinogenic. Only a 500-mL bottle (working stock) may be kept outside the Carcinogen Laboratory, and it must be stored in a labeled secondary container in a designated hood to prevent worker exposure during pipetting.

- Concentrated ammonium hydroxide and acetic acid are caustic and volatile and should be added to water or water/alcohol solutions in a fume hood.

1. Place no more than four DALT gels to a box, and cover them with $1 \mathrm{~L}$ of $50 \%$ ethanol containing $1 \%(\mathrm{v} / \mathrm{v})$ acetic acid and $0.1 \%(\mathrm{v} / \mathrm{v})$ formaldehyde. Let them sit in this solution for at least $6 \mathrm{~h}$ to fix the proteins. Then remove the solution and pour it into the waste container for ethanol solutions that contain formaldehyde but not silver.

2. Add $1 \mathrm{~L}$ of $50 \%$ ethanol and rock the gels overnight. (The gels may stay in the $50 \%$ ethanol for 2 to 3 days before proceeding with staining, and in fact the backgrounds of the gels may be lighter after a longer period in the 50\% ethanol.) After this ethanol immersion, the $50 \%$ ethanol is decanted into the same waste container as in step 1 above. 
3. Rinse the gels in $1 \mathrm{~L}$ of $20 \%$ ethanol for $30 \mathrm{~min}$, and then rinse them again for $30 \mathrm{~min}$ in $1 \mathrm{~L}$ of $20 \%$ ethanol containing $5 \mathrm{mg} / \mathrm{L}$ of dithiothreitol (DTT). The first $20 \%$ ethanol rinse may be poured down the sink, but the second rinse (containing DTT) must be poured into the waste silver drum.

4. For each box of four gels, mix $940 \mathrm{~mL}$ of $20 \%$ ethanol with $1.41 \mathrm{~mL}$ of $10 \mathrm{~N} \mathrm{NaOH}$ on a stirring plate. In another beaker, dissolve $4.0 \mathrm{~g}$ of $\mathrm{AgNO}_{3}$ (silver nitrate) in $50 \mathrm{~mL}$ of water. Just before use, add $10.5 \mathrm{~mL}$ of $\mathrm{NH}_{4} \mathrm{OH}$ (ammonium hydroxide) to the ethanol solution, and then add the silver solution. A brown precipitate will form, which will clear quickly. (If the precipitate does not clear, discard the solution and start over.) Pour this solution over the gels and shake them for $1 \mathrm{~h}$ at room temperature. This silver incubation solution is decanted into the waste silver drum after use.

5. After incubating, wash each box three times with $1 \mathrm{~L}$ of $20 \%$ ethanol, $20 \mathrm{~min}$ for each wash. Each of the three wash solutions should be decanted into the waste silver drum.

6. Develop the gels for up to $20 \mathrm{~min}$ with a solution of $50 \mathrm{mg}$ of citric acid and $0.5 \mathrm{~mL}$ of formaldehyde in $1 \mathrm{~L}$ of $20 \%$ ethanol. The formaldehyde should be pipetted into a large mixing pitcher in the hood immediately before use. When silver staining gels with unfamiliar samples, watch the proteins in the gels develop and stop the reaction when the spots vs. background are optimal (generally 10-20 min.). If the solution appears cloudy or if a precipitate forms at the beginning of the development process, rearrange the gels in each box by pulling the bottom gel up to the top until all the gels have been moved - this will help to evenly distribute the silver throughout the gels. After developing is complete, this solution should be poured into a waste silver/ethanol/formaldehyde container.

7. Stop the development by adding $1 \mathrm{~L}$ of $0.5 \%(5 \mathrm{~mL} / \mathrm{L})$ acetic acid in water and letting the gels shake for five additional minutes. This waste is poured into the waste silver drum.

8. Wash the gels with $1 \mathrm{~L}$ of water three times for 15 min each time. The first wash is in double-distilled water, but the next two washes can be in tap-distilled water. The gels can be carried in the boxes with the third wash to the scanning room. The first two washes are decanted into the waste silver drum. Be sure all waste is recorded in the log book.

9. If gels are to be digitized, scan with the Eikonix 1412 scanner (without any filter) immediately after the final 15-min wash. Photograph gels and dispose of the final rinse water in the Metafix fixer batch tank for silver recovery. 


\subsection{AUTORADIOGRAPHY}

\subsubsection{Staining the Gels}

1. Gels are stained with Coomassie blue (see Section 4.1) and are destained in two washes of $20 \%$ ethanol. (For autoradiography, the gels do not need to be completely destained [the proteins just need to be fixed], so one or two changes of ethanol are enough.)

The stain solution and first destain solution must be disposed of as liquid radioactive waste, but the second destain may be disposed of down the drain if Health Physics finds no detectable radioactivity.

2. Destained gels are shaken in $2 \%$ glycerol for $30 \mathrm{~min}$, changing the glycerol solution once after $15 \mathrm{~min}$. The glycerol prevents the gels from cracking badly when they are dried.

\subsubsection{Drying the Gels Using the Virtis Freezemobile and the BioRad Gel Dryer}

1. Make sure the manifold, chamber, condenser, and drain line of the Virtis Freezemobile lyophilizer are clean and dry. Check the level and clarity of the vacuum pump oil. Close all valves, drain plugs and doors. Check that the line voltage is correct for the equipment (Sentry Point LV, which should read approximately 190).

2. Turn on the lyophilizer's refrigeration unit and allow it to chill the apparatus to about $-60^{\circ} \mathrm{C}$. The Sentry will display the condenser temperature as $\mathrm{C} 1$, and an $\mathrm{OK}$ status light will come on when the low temperature has been reached and it is safe to proceed (about $15 \mathrm{~min}$ ). The run timer will start when the refrigeration switch is turned on, and the accumulated time will be displayed as RT.

3. Turn on the vacuum. The Sentry will display the vacuum as point "V1." The vacuum status light will not indicate "OK," so wait until the vacuum pulls down to approximately $500 \mathrm{mT}(66.7 \mathrm{~Pa})$.

4. The BioRad Model $583 \mathrm{Gel}$ Dryer is connected by vacuum tubing to a port on the lyophilizer. Turn on the gel dryer by using the switch on the back. At this point, the display on the dryer will read "OFF." The function of the vacuum in drying is to hold the gel rigidly in place and also to decrease the pressure around the gel (to facilitate evaporation of the bound water in the gel). 
5. There are three drying cycles on the dryer. The first is the standard cycle for drying 2DE gels. This cycle raises the temperature to a preset value and holds this temperature throughout the cycle. (The two other settings are for drying DNA sequencing gels and high-percentage acrylamide gels.) Make sure the cycle display light is on in front of the first choice (indicated by the symbol " $\sqcap$ ").

6. After the cycle has been selected, press the temperature button. The drying temperature from the previous run will be shown on the LED display, but after $3 \mathrm{~s}$ the LED will read "OFF" and the button must be pushed again to turn it on. The dryer's default temperature is $80^{\circ} \mathrm{C}$. Reset the temperature to $75^{\circ} \mathrm{C}$ for gel drying (found to be the optimal temperature in this laboratory). To change the temperature, press the temperature button twice in rapid succession. The light above the temperature button will flash, and the temperature used for drying the gel can be adjusted with the "raise" and "lower" buttons.

7. Press the time button to set the length of time the gel will be dried. When this button is pressed, the light above the time button will be lit and the amount of time used for drying the last gels will be shown. When the power is first turned on, the dryer defaults to a 2-h set point. It is optimal to dry gels for $1.10 \mathrm{~h}(1 \mathrm{~h}, 6 \mathrm{~min})$, so press the time button twice in rapid succession. The light above the button will flash, and the drying time can be adjusted by using the "lower" button.

8. Open the dryer and lay aside the transparent sealing gasket. To ensure a good vacuum seal, wipe the transparent gasket with a damp cloth and clean the sealing track where the gasket contacts the dryer base.

9. Line up a dry sheet of filter paper backing on top of the porous gel support; the paper can be reused several times.

10. Place a thick Mylar ${ }^{\circledR}$ sheet on a countertop to help hold the gels in place. Place four gels, face down, on the sheet. Trim about $1 \mathrm{~cm}$ off the top of each gel and smooth the gel surface with gloved fingers to remove bubbles trapped between the gel and the sheet. Make a note of the four gel numbers. and their locations on the filter paper, because sometimes the numbers become illegible when they dry.

11. Cut a piece of filter paper to the size of the dryer gel support, and place it carefully over the four gels positioned on the Mylar ${ }^{\circledR}$. Pat it down carefully to position it on the gels. At this point, do not try to slide the filter paper or reposition the gels.

12. Flip the entire "gel sandwich" over and place it directly on top of the reusable filter paper backing on the gel drying support. 
13. Cover the Mylar ${ }^{\circledR}$ sheet with the transparent sealing gasket and smooth it down carefully.

14. Open the appropriate vacuum port. Check to be sure that there are no leaks and that a vacuum is being created. It is easier to get a good seal by using the lid to press down all around the edge of the gasket than by trying to seal it by hand.

15. Start the run by pressing the "START" button. The machine will turn off automatically.

16. After drying is completed, allow the system to cool down before unloading the gels. Lifting the lid of the dryer will speed the cooling process. It is very important that the gels be completely dry before the vacuum is released, or the gels will crack.

17. To unload the gels, close the port that goes to the gel dryer. Lift the transparent sealing gasket aside and peel off the Mylar ${ }^{\circledR}$ sheet, exposing the four dried gels face up.

18. Repeat steps 8-17 until all of the gels have been dried.

Once the time and temperature parameters are set, they will be retained in memory until changed or until the power is turned off. To repeat a run, simply press the start button. When a gel is not being dried, the dryer only uses $15 \mathrm{~W}$ of power, so the power can be left on for the convenience of being able to repeat routine drying cycles by pushing a single button. Only turn the main switch off if the dryer will not be used for several weeks.

\section{CAUTION}

Never turn off the vacuum switch before releasing the vacuum, or oil will be sucked into the vacuum chamber, with serious consequences.

19. After all the gels have been dried, release the vacuum in the lyophilizer by opening a port; then turn off the vacuum switch and refrigeration switch. Open the bottom front door; open the drainage tube and insert it into the waste bottle. Turn on the defrost switch, which will heat the inside of the chamber quickly and allow an intact "cylinder" of ice to be lifted out within an hour or so. Otherwise, the ice can be left to melt and the water collected in a waste bottle. Once the melted ice is drained, wipe the chamber dry. 
After the gels are dried and the chamber is empty and dry, get the system ready for the next set of gels to be dried by following steps 20-23.

20. Check the vacuum pump oil level and clarity. The level of the oil should be at least halfway up the sight glass. If the oil looks cloudy or dirty, change it. Also, drain approximately $20 \mathrm{~mL}$ from the drain hose into a beaker and check for water.

21. If the oil in the pump needs changing, first open the top porthole with the large Allen wrench, and then open the drain hose at the bottom of the pump (preferably when the oil is still quite warm), draining the oil into the waste oil beaker. Place the waste oil in a waste bottle and requisition Waste Management to dispose of it. When the pump is almost completely drained, add approximately $25 \mathrm{~mL}$ of new oil, screw in the top port screw by hand, turn on the vacuum switch for about $5 \mathrm{~s}$ to clean the inside of the pump, and drain this oil into the waste beaker.

22. Fill the pump with fresh oil by using a funnel and pouring vacuum pump oil (approximately $1 \mathrm{~L}$ ) into the top port until the level is correct, most of the way up the front sight glass.

23. There is also a "purge" switch on the lyophilizer, which is an electrically operated valve to isolate the vacuum pump from the freeze dryer's vacuum system. Using the purge process for $1-2 \mathrm{~h}$ helps to get rid of water and other volatile contaminants from the pump oil. The purge is on when the purge switch is moved to the left, marked " 1 ." The purge is off when the switch is moved back to the right, marked " 0 ." Purging the oil after changing it gets rid of any residual moisture in the pump and prolongs the life of the oil, as well as that of the pump.

\subsubsection{Loading the Dried Gels onto Film}

1. Cut apart the four dried gels. Label each gel with the appropriate number using Radtape Plus phosphorescent adhesive labels (Diversified Biotech, Boston, Massachusetts; catalogue no. ADP-200) cut to fit the corner of the gel; write the numbers on the tape with a felt-tip pen. Expose the tape to bright room lights while labeling the gels, or else expose the Radtape to bright light for $10 \mathrm{~s}$.

2. In the inner dark room with only the safelight on, place a dried gel on film and insert into either a cardboard or metal film cassette. The film may be Kodak XAR-2 (catalogue no. 165 1579), which gives a light gray background, or Fuji RX (Fisher catalogue no. 04-441-95), which gives a clear light blue background. 
For Kodak film, tear off the side blue strip, insert the dried gel between the film and the loose paper of the Ready Pack, and place it in a film cassette. For Fuji film, place the gel on a piece of film and place it carefully in a film cassette; the use of the interleaf sheets that come in the Fuju box is optional.

Put ${ }^{35} \mathrm{~S}$-labeled gels into cardboard cassettes, no more than two gels per cassette, and place each cassette in an empty slot on the "gel squasher." Open the valve attached to the slot's air bag, and the film cassette and contents will be squashed flat by air pressure, so that the gel is evenly exposed to the film during the room-temperature autoradiography period.

Put ${ }^{32} \mathrm{P}$-labeled gels into a metal film cassette with an intensifying screen (one gel per cassette), close the cassette, and store in the $-70^{\circ} \mathrm{C}$ freezer for the chosen exposure period.

Exposure time depends on the amount of isotope in the sample. Record the date, time, sample, and initials in the log book.

\subsubsection{Developing the Autoradiographs}

1. Develop the autoradiographs in the Xomat Model M35A. Sign in on the logsheet located on top of the Automixer next to the Xomat.

2. Turn on the Automixer by pushing the master button down.

3. Remove the top cover of the Xomat. Place the two sets of rollers in the appropriate positions (the developer crossover rollers are gray rubber, and the fixer crossover rollers are tan). Place the appropriate evaporation covers on top of the rollers, and replace the top cover of the processor.

4. Flip up the master power switch on the wall above the Xomat. The main power switch on the processor should be on all the time; do not touch it!!

5. Turn the two yellow "Apollo" valve handles to the left of the Xomat parallel to their pipes. This turns on the water to both the Xomat and the Automixer.

6. Inside the inner dark room, turn the yellow "Apollo" valve on just until you hear water running (any more than that will cause the silver-recovery and $\mathrm{pH}$-adjustment filters to leak, flooding the floor). 
7. Turn on the safelight (if the film permits the use of any light) by the switch on the cord near the left rear corner of the bench in the inner darkroom. Keep the outer darkroom lights turned off when processing film.

8. Wait about $15 \mathrm{~min}$ for the machine to warm up. The temperature "ready" light flashes when the developer solution is at the correct temperature for processing film (about $33^{\circ} \mathrm{C}$ ).

9. Prior to putting film through the Xomat, press the "run/standby" button on the front of the machine to activate the rollers. After film has gone through the machine, the processor will automatically return to the standby mode.

10. In the inner darkroom, feed two sheets of cleanup film through the processor to clean the rollers. Sheets may be put back in the box to be reused as long as they are still clean.

11. Feed an autoradiograph into the processor. When using single-emulsion film, feed it emulsion side down. Most films are double emulsion, so it does not matter which side is down going into the machine. When the film is introduced into the machine, the red safelight attached to the processor will go off, and it will come back on to signal that the next piece of film can be fed in. Continue until all the film has been fed through the machine, and wait until the processor's safelight turns on before turning on the room light. Turn off the main safelight in the inner darkroom.

12. When the Automixer alarm beeps, check its indicator lights to see which solution is depleted. Replenish with the appropriate solutions (color-coded and stored in boxes along the wall). With the water still turned on, take the caps off the bottles and invert them into the proper spaces in the Automixer; do not remove the seals from the bottles prior to inverting. After the solution has emptied into the Automixer, rinse and discard the bottle(s) and allow approximately $10 \mathrm{~min}$ for mixing before feeding more film through the processor.

13. To shut down the machine, turn off the main power switch on the wall, and shut off the three Apollo valves for the water supplies. Turn off the Automixer switch by pushing the master button; it will pop up.

14. Remove the top cover of the Xomat. Remove the evaporation covers, take out the developer and fixer crossover rollers (being careful not to twist them out of square or disturb the guide shoes), and rinse them all at the sink. 
15. Leave the rollers on the sink to dry, and reinstall the top cover, leaving it open about 2 in. $(5 \mathrm{~cm})$ to vent any fumes and heat.

\subsubsection{Disposing of the Gels}

To save dried gels for possible future use, pack them tightly into a file drawer so they do not curl or crack, or store a stack of dried gels in the gel squasher until you are done using them. Store radioactive dried gels in a controlled area for several half-lives until Health Physics determines they are no longer radioactive and can be thrown in the trash. Nonradioactive gels may be thrown in the trash after the photography and printing steps are complete. 


\section{PHOTOGRAPHIC TECHNIQUES}

This discussion of photographic techniques is specific to Argonne instruments and procedures. However, it should provide useful information about general procedures for any lab. When in doubt, please refer to the manuals for your specific instruments.

\subsection{PHOTOGRAPHING GELS}

1. Turn off the room light. Turn on both light boxes. Place a slab gel on the translucent glass plate so that the right side of the gel is against the alphabet strip and the gel number is in the lower right corner. Write the gel series number on a piece of tape at the top of the alphabet strip. Use the small movable arrow to identify the specific letter corresponding to the gel being photographed.

2. Remove all air bubbles carefully, pushing them out from under the gel by running your finger across the surface of the gel. (Bubbles show up as gray spots on the pictures.)

3. Place the glass plate on the light box under the camera.

4. Focus the camera on the alphabet strip by using the front viewer with the camera setting on "B" (shutter open). Position the glass plate so that the gel slab lies between the marks on the light box, ensuring the illuminated area encompasses the gel and alphabet strip. Close the shutter by changing the camera setting to " $1 \mathrm{s."}$

5. For photographing Coomassie-blue-stained gels, use high-contrast $4 \times 5$-in. Technical Pan Film (Kodak catalogue no. 800 4640). Take photographs using a 1-s exposure at $f 16$ or $f 11$ through an interference filter ( $550 \mathrm{~nm}$ narrow band; Baird-Atomic, Inc.). For densitometry or for photographing silver-stained gels, autoradiographs, or printed material for publication, use the lower contrast $4 \times 5$-in. Plus-X film (Kodak catalogue no. 144 3167). Take photographs on Plus-X film using a one-eighth- or one-fifteenth-second exposure at $f 22$, without the interference filter.

6. The $4 \times 5$-in. film holders each contain two sheets of film. The dark slides (which protect the film from light) have a bumpy side and a smooth side. The bumpy side indicates that there is unexposed film in the cartridge, and the smooth side indicates exposed film in the cartridge. 
Insert a film holder that has the bumpy side of the slide showing into the springloaded track on top of the camera. Remove the lower dark slide. Take the picture and reinsert the dark slide with the smooth side to the outside of the film holder to indicate that the film is exposed. Remove the film holder from the track and turn it over. Remove the dark slide, expose the new sheet of film, and replace the dark slide, smooth side out. Then remove the film holder and insert a new one into the camera. It is good practice to develop the first few films to ensure that the film processor is working properly and that the exposure time is optimal.

7. Continue taking pictures until all gels in the box have been photographed. As each gel is photographed, put it with the "finished" gels into a separate box of water. Remember to slide the arrow along the alphabet strip on the glass plate to properly identify each gel.

8. When the photography is finished, close the top of the camera to keep out dust, and turn off the light boxes.

\subsection{DEVELOPING FILM USING THE HOPE FILM PROCESSOR MODEL RAX 2044V}

The simple instructions that follow only apply to the everyday functioning of the Hope film processor (RAX 2044V). There is a complete installation/instruction/troubleshooting manual that goes into great detail about setup and resetting parameters on the control panel. If any problems occur which are not covered by these simple instructions, refer to the product manual, but see the staff before changing anything.

1. The lid should be left ajar from previous use. Remove the lid and lid support and check the solution levels.

\section{CAUTION}

Never add water to the tanks, because it will adversely alter the chemistry of the solutions.

Replenish both the developer and fixer tanks from the stock replenishment solutions as needed. If only a small amount of chemical is needed to replenish the tanks, press the manual "replenisher" button on the control panel, and $30 \mathrm{~mL}$ of solution will be delivered to each tank. Replace the processor's top cover.

2. The speed control function provides four sets of speed/replenishment parameters. Speed is displayed as the length of time (in seconds) that the film is in the developer. 
Replenishment is displayed as milliliters per square foot of film. Setup \#1 is preset at $100 \mathrm{~s}$, to process Plus-X film; setup \#2 is preset at $55 \mathrm{~s}$ to process Technical Pan film. Both setups use a $60-\mathrm{mL}$ replenishment amount. These variables were determined by trial and error with each kind of film. There are two other setup points for this machine to allow for other film processing. Please see the staff for help before changing anything on the control panel.

3. Turn on the power at the control panel. Allow the processor to warm up (20-30 min). During this time the wash tank will refill (the water drains out during shutdown). Once the "ready" LED goes on to indicate that chemicals are the proper temperature, press the "help" button on the control panel to see whether there are any error or problem messages displayed. Problems must be corrected before the machine will operate properly. Feed several clean-up sheets or old $\mathrm{x}$-ray films through the machine to clean the rollers. (It is possible to do this step before the machine has warmed up, but a continuous beep will sound to indicate that the solutions are not warm).

4. When the processor is warmed up ("ready" lights come on), press the "display off" button so that the lighted LED control panel becomes dark; even that small amount of light will fog the film. Then, begin feeding film for processing. The machine will change from standby to run mode, and all the pumps and fans will turn on. For $4 \times 5$-in. film, two or three pieces of film, emulsion side down, may be fed into the entry tray side-by-side. The film transport system will grab the film. Wait until three quick, consecutive beeps signal that more film can be fed into the machine. The machine goes into standby after the last piece of film exits from the dryer, and the pumps will shut down. Before turning on the lights, it is good practice to feel across the feed tray; occasionally a piece of film does not actually go into the machine, but sticks in the feed tray.

5. Reload any empty film cassettes with the proper type of film, and put the cassettes into the drawers in the photography room for the next person. Do not leave empty film cassettes in the darkroom.

6. For daily shutdown, after all material has exited from the dryer, press the on/off key. The wash tanks automatically drain after the programmed delay time. Prop up the cover to ventilate the processor.

\subsection{PRINTING WITH THE ILFOLAB MODEL 2150RC PRINTER}

1. Start with the room lights on. Remove the lid support, and close the lid on the printer. Turn the machine on by moving the proper knob to the right. Open the blue water 
valve against the wall, which feeds rinse water to the machine, by moving the handle so that it runs parallel to the hose. It will take about $25 \mathrm{~min}$ for the printer to warm up. The processor will not accept any paper until the "ready" light changes from flashing to steady.

2. If the printer has not been used for awhile, send two pieces of Kodak Roller Transport Cleanup Sheets 4955 through the machine. These sheets can be put back in the box to be reused unless they appear very streaked or dirty.

3. Turn off the room light, turn on the two safelights by using the switches on the cords, and turn on the enlarger light ("focus" switch). Turn on the Macbeth densitometer to check the exposure of the final print.

4. Snap a negative in the negative holder with the emulsion side down. The notch will be in the upper right corner. Place the holder up in the enlarger just under the large condenser lenses.

5. Adjust the size of the picture with the appropriate knob. With the diaphragm wide open, focus by looking through the "Magnisight" at the alphabet strip next to the gel (it is easier to focus on letters than on spots). After focusing the enlarger, turn the diaphragm back about a quarter- or half-turn to cut down on light. You may use a light meter for this step or just approximate the level.

6. Set the timer for 2-8 s. Turn the focus switch to "time." Take an $8 \times 10$-in. sheet of Ilford RC Deluxe Multigrade IV (for higher contrast results) or Kodak Kodabrome II RC (catalogue no. 192-2608 [F-3] or 192-1337 [F-2]) (for lower contrast results) from the black envelope inside the box, and slip the paper into the easel guide with the emulsion (shiny) side up. Press the timer button on the right of the control box.

7. When the light goes off, remove the paper from the easel, turn it over (shiny side down), and guide it into the feed tray on the printer. It is important to have the emulsion side down, or the dryer will melt the emulsion on the rollers. A "beep" will sound when the next sheet of paper can be fed into the machine.

8. Check the quality of the first print. If the print is too dark, decrease the light by using (a) one-half the previous time, or (b) the same time at the next smaller lens opening, which is a higher $f$-stop number on the lens.

9. After the picture appears to have a good background density, close the box of paper and check the background density using the Macbeth densitometer. The optimal reading should be 1.12 to 1.2 with the null light on. The white edge of the paper 
should read 0.95 to 1.0 . Once the settings are established on the first print, they should be the same for all the other negatives in the set, and the rest of the photographs can be printed quite rapidly. There are sample prints posted for comparison. Uniformity of background in prints is important in order for any comparison of spots to be made. At this time, also check for dirty prints or blue-gray streaks.

10. When printing is complete, make sure that all the paper is put away and the box is closed before turning on the room lights.

11. Turn off the printer and lift up the top. Squirt the developer and fixer rollers with water to remove any chemicals, and leave the top propped open with the metal door support to allow ventilation. Turn off the blue water valve on the wall behind the printer.

The Iffolab processor functions best when it is maintained properly. The paper (especially the Kodak paper) is very sensitive to roller smears and marks, so the machine and rollers should be cleaned thoroughly. If any roller marks show on the prints, it is time to take the three sets of rollers out of the machine and clean them at the sink with warm water and a soft paper towel until no more black residue comes off on the towel.

All solutions should be drained every 2-4 weeks, depending on the amount of use. The steps for changing the solutions are as follows.

12. Lift the lid of the printer and prop it open with the rod located under the lid. Drain the fixer first, then the developer, and finally the wash water. Drain one tank at a time by releasing each one of the five standpipes until all have been released. The fixer hose must be placed in a 5-gal collection bottle, so that the fixer solution can be poured into the Metafix batch tank across the hall for recovering the silver. The water and developer tanks are drained down the sink, as they are not hazardous. Retighten all standpipes after the tanks are empty.

13. Switch the processor on. The "warning" light will remain on during the initial systems check. For the automatic rinsing step, press the water feed button and hold it for $3 \mathrm{~s}$ until water flows. Lower the processor lid. The processor automatically fills with water, runs for $2 \mathrm{~min}$, and then gives three audible signals and stops. Switch the processor off and drain all tanks again. This time the fixer wash water can be put down the drain.

14. To refill the tanks, pour the contents of one bottle each of developer and fixer concentrate into the appropriate front tanks. Bottles and tanks have color-coded 
labels, red for developer and green for fixer. Switch the processor on, and press the water feed button for $3 \mathrm{~s}$ until water flows. Lower the processor lid.

15. The processor automatically dilutes, mixes, and heats the solutions. The processor is ready for use again when the "ready" light changes from flashing to steady on, and an audible signal is given; this will take approximately $30 \mathrm{~min}$. Note the solution changes on the calendar. 


\section{TRANSFER OF PROTEINS FROM 2DE GELS TO PVDF MEMBRANES}

Proteins can be transferred out of 2DE gels onto membrane supports for further analysis by, for example, immunoblotting (Western blots) or amino-terminal amino acid sequencing. The membranes of choice are nitrocellulose or polyvinylidene difluoride (PDVF). The following methods are for PVDF membranes (Matsudeira 1987). Methods for the use of nitrocellulose membranes can be found in earlier editions of this manual.

Two kinds of PVDF membranes are used for transferring proteins from 2DE gels. Immobilon-P membranes (Millipore Corporation, Bedford, Massachusetts; catalogue no. IPVH $15150[15 \times 15 \mathrm{~cm}])$ are used mainly for doing Western blots, while ProBlott membranes (Applied BioSystems, Foster City, California; catalogue no. $400994[20 \times 20 \mathrm{~cm}]$ ) are used for transferring proteins for sequencing. Gloves must be worn at all stages of the transfer operation, since proteins from fingers will be bound to the membranes. The solutions that contain methanol which are used in transferring proteins from 2DE gels to PVDF membranes must be discarded as hazardous waste. The proteins bound to PVDF are stable for an indefinite time on dry membranes stored at $-20^{\circ} \mathrm{C}$.

\subsection{TRANSFERRING THE PROTEINS TO MEMBRANES}

1. After $2 \mathrm{DE}$ is complete, equilibrate the gels in $10 \mathrm{mM}$ 3-(cyclohexylamino)-1propanesulfonic acid (CAPS) transfer buffer ( $\mathrm{pH} 11.0$ ) containing $10 \%$ methanol (approximately $50 \mathrm{~mL}$ per gel) for 5-10 min. When the CAPS transfer buffer is made, it will be approximately $\mathrm{pH} 5$, so several milliliters of $10 \mathrm{~N} \mathrm{NaOH}$ will be needed to bring the $\mathrm{pH}$ to 11 .

2. Trim the pieces of membrane and filter paper to match the size of the gel to be transferred. Use a permanent marker to write an $\mathrm{ID}$ number on the lower right corner of the membrane. (The ink will run a bit when the membrane is placed in methanol, but the mark will still be visible permanently.)

3. Wet the membranes in $100 \%$ methanol for a few seconds and then place them in a box containing CAPS transfer buffer. Wet several Gel Blott paper squares (Midwest Scientific, Valley Park, Missouri; catalogue no. 3MWO-1616) in another box containing the CAPS transfer buffer. Seven squares of blotting paper are used to transfer three gels.

4. Trim one gel at a time to the size of the membrane. Trimming is easily done (using a single-edge razor blade) on a plastic sheet that has the membrane size drawn on it with a marking pen, creating a template. Make sure that the gel is oriented with the gel designation number in the lower right hand corner, since the $\mathrm{ID}$ number will be 
cut off. Rinse the trimmed gel in a fresh box of CAPS transfer buffer, taking care to keep the gel correctly oriented.

5. Make a gel "sandwich" on the semi-dry electroblotting apparatus (such as the Hoeffer [San Francisco, California] SemiPhor Semi-Dry Transfer Unit TE 70 or TE 77) by first positioning the mylar mask properly over the anode electrode surface. Then place two pieces of the wet filter paper squares on the bottom of the transfer apparatus and start loading the "sandwich." The sandwich consists of one wet filter paper square (thus there are actually three pieces of wet filter paper on the grid), then the PVDF membrane with the number in the lower right corner, then the gel properly oriented. The next sandwich of filter paper, PVDF membrane, and gel can then be added. For optimal results, stack no more than three sandwiches per apparatus. Proteins move down from the gel into the membrane, since the anode $(t)$ is on the bottom and the cathode $(-)$ is in the lid of the apparatus.

6. After the last sandwich is stacked, add two more pieces of wet filter paper on the top of the pile, and place the lid on the apparatus. There is a safety wire connecting the lid to the bottom of the unit so that the lid cannot be removed during a run.

7. Plug the electrodes into the front of the power supply (red wire plug into the red female connection and black wire plug into the black female connection). Turn the switch on. Turn the knob until the voltage reads 7-9 V and the amperage remains at 110-130 mA. There is a toggle switch on the front of the power supply to switch back and forth between voltage and milliamperage readings. Place a heavy object (approximately $1 \mathrm{~kg}$ ) such as a bottle of Tris powder on top of the unit to place pressure on the sandwiches to ensure good contact.

8. Allow electrophoretic transfer to take place for $1.5-2.5 \mathrm{~h}$ at $7-8 \mathrm{~V}$. Use the shorter time if only one or. two gels are being transferred. Check the power supply periodically throughout the run to see if the voltage has increased significantly. The voltage tends to increase and may have to be turned down to prevent the gels from getting too warm or dry. Heat causes bubbles to form and interfere with the transfer process.

9. When the transfer is complete, turn the voltage knob completely to the left, and turn the power switch off. Remove both electrode wires from the power supply, and remove the interlocking safety wire from the lid to the bottom of the setup. Carefully pull the lid off the transfer apparatus (part of the sandwich may come up with the lid).

10. Start unstacking the sandwich. Discard the blotting paper with the general solid waste. The gels are usually discarded, but they can be checked to see how well the 
spots transferred by staining them with Coomassie blue (see Section 4.1). Place the membranes either in blocking solution or Coomassie blue, depending on the intended use of the membrane.

Make blocking solution fresh for each experiment, because it gets moldy when stored. Milk is a low-cost alternative for blocking, but it should not be used as a diluent for antibodies used in the Western blot procedures; always use Tris-buffered bovine serum albumin (BSA) for antibody dilutions.

Place the membranes in a non-reactive blocking solution (e.g., 10\% BSA [recipe 26] or 3\% nonfat dry milk [recipe 29]) and leave them overnight in the refrigerator. The next day, remove the membranes from the refrigerator. If Immobilon membranes will be used for Western blots (immunostaining), follow the procedure in Section 6.2. If the membranes will not be used for Western blots, rinse them with saline and hang them up to dry.

If Coomassie blue staining will be used because the complete pattern on the membranes needs to be seen, follow these steps after the gel sandwich is unstacked.

1. Rinse the membranes in double-distilled water. Then saturate the membranes in a box of $100 \%$ methanol for a few seconds.

2. Stain the membranes for about $1 \mathrm{~min}$ in a box containing $0.1 \%$ Coomassie blue $\mathrm{R}-250$ in $40 \%$ methanol $/ 1 \%$ acetic acid (approximately $200 \mathrm{~mL}$ per three membranes).

3. Destain the membranes in two to three fresh changes of $50 \%$ methanol (approximately $200 \mathrm{~mL}$ per wash; three membranes per wash).

4. Rinse extensively with water at the sink, and hang the membranes up to dry with the magnetic clips lined up along the metal shelves by the sink.

\subsection{IMMUNOSTAINING ON IMMOBILON MEMBRANES (WESTERN BLOTS)}

1. If the membrane has been dried prior to staining, rewet it in $100 \%$ methanol, rinse it in water, and equilibrate it in $10 \mathrm{mM}$ Tris/saline (recipe 30) for about $20 \mathrm{~min}$. Otherwise, pour off the BSA blocking solution and use it to dilute the primary antibody approximately 1:100 or greater (depending on the antibody). Pour $50 \mathrm{~mL}$ over the transfer membrane. Leave on the shaker at room temperature for $1 \mathrm{~h}$.

2. Pour off the antibody. Freeze at $-20^{\circ} \mathrm{C}$ for future use, if desired. Rinse the transfer membrane five times with saline to wash off all traces of unbound antibody. 
3. Add the appropriate anti-IgG-peroxidase diluted 1:1000 in blocking solution as the secondary antibody. For example, if the primary antibody was rabbit anti-human, then use goat anti-rabbit IgG-peroxidase. Concentrated solutions of these conjugates are in the $-20{ }^{\circ} \mathrm{C}$ freezer. Rock the transfer membrane in this solution at room temperature for $1 \mathrm{~h}$.

4. Discard the solution and rinse the membrane five times with saline to remove excess secondary antibody.

NOTE: Do not make the following solutions unless you are prepared to use them immediately. They cannot be frozen because a precipitate will form.

5. To stain two to three membranes, prepare the following two solutions:

- Dissolve $60 \mathrm{mg}$ of 4-chloro-1-naphthol (BioRad, catalogue no. 170-6534) (or two $30-\mathrm{mg}$ tablets [Sigma catalogue no. C6788]) in $20 \mathrm{~mL}$ of methanol.

- Add $60 \mu \mathrm{L}$ of $30 \% \mathrm{H}_{2} \mathrm{O}_{2}$ (hydrogen peroxide) in $100 \mathrm{~mL}$ of cold $20 \mathrm{mM}$ Tris/saline ( $\mathrm{pH} 7.5)$.

Add the hydrogen peroxide to the cold Tris/saline just before mixing the solution with naphthol solution. Mix the two solutions at room temperature and use immediately. Pour the mixture over the first transfer and agitate it until staining is adequate (blue spots with white or light blue background). The stain solution can be used to stain a second and third membrane if desired.

6. Rinse the stained membranes well with tap-distilled water to stop the reaction. Pour the stain solution into the designated waste container, because it contains methanol.

7. Photograph the wet transfer membranes using the 550-nm green filter and reflected light from the two floodlights. Use about a 0.5 -s exposure at $f 11$ for Technical Pan film. The darker the transfer background, the longer the exposure you will need. The stained transfer may be air-dried and stored indefinitely; however, the stained spots fade with time.

\subsection{AMINO TERMINAL AMINO ACID SEQUENCING}

When PVDF membranes are transferred for sequencing, they are stained with Coomassie blue and destained as described for Immobilon membranes in Section 6.1 (p. 52, steps 1-4). The 
membranes will dry in about $3 \mathrm{~h}$ when hanging by clips over the sink. The membranes will have a light background, so the blue protein spots of interest can be cored out with a scalpel and placed in a vial. Use forceps to handle the pieces. Store the dried membranes (interleaved with protective paper) and vials of cored spots at $-20^{\circ} \mathrm{C}$ until sequencing is to be done.

NOTE: Protein samples blotted onto ProBlott membranes can also be detected by using Ponceau S, amido black, immunostaining, or lectin staining (for glycoproteins). Check with the ProBlott instruction pamphlet which comes with each set of membranes if staining other than Coomassie blue is desired. 


\section{REFERENCES CITED}

Guevara, J., S. Capetillo, D.A. Johnston, B.A. Martin, L.S. Ramagli, and L.V. Rodriguez, 1982, Quantitative aspects of silver deposition in proteins resolved in complex polyacrylamide gels, Electrophoresis 3:197-205.

Matsudeira, P., 1987, Sequence from picomole quantities of proteins electroblotted onto polyvinylidene difluoride membranes, Journal of Biological Chemistry 262:10035-10038.

Miller, D.M., 1990, Buffer solutes as stabilizers of ${ }^{35}$ S amino acids - a study of volatility, radiochemical purity, and biological activity, Biotechniques 9:592-596.

O'Farrell, P.Z., H.M. Goodman, and P.H. O'Farrell, 1977, High resolution two-dimensional electrophoresis of basic as well as acidic proteins, Cell 12:1133-1142.

Ramagli, L.S., and L.V. Rodriguez, 1985, Quantitation of microgram amounts of protein in twodimensional polyacrylamide gel electrophoresis sample buffer, Electrophoresis 6:559-563. 


\section{SELECTED REFERENCES FROM ARGONNE 2DE RESEARCH (grouped by year of publication)}

Anderson, L., and N.G. Anderson, 1977, High resolution two-dimensional electrophoresis of human plasma proteins, Proceedings of the National Academy of Sciences USA 74:5421-5425.

Anderson, N.G., and N.L. Anderson, 1978, Analytical techniques for cell fractions. XXI. Twodimensional analysis of serum and tissue proteins: multiple isoelectric focusing, Analytical Biochemistry 85:331-340.

Anderson, N.L., and N.G. Anderson, 1978, Analytical techniques for cell fractions. XXII. Twodimensional analysis of serum and tissue proteins: multiple gradient-slab gel electrophoresis, Analytical Biochemistry 85:341-354.

Anderson, N.G., N.L. Anderson, and S.L. Tollaksen, 1979, Proteins of human urine. I. Concentration and analysis of two-dimensional electrophoresis, Clinical Chemistry 25:1199-1210.

Anderson, N.G., et al., 1979, Analytical techniques for cell fractions. XXV. Concentration and two-dimensional electrophoretic analysis of human urinary proteins, Analytical Biochemistry 95:48-61.

Anderson, N.L., and B.J. Hickman, 1979, Analytical techniques for cell fractions. XXIV. Isoelectric point standards for two-dimensional electrophoresis, Analytical Biochemistry 93:312-320.

Edwards, J.J., et al., 1979, Red cell proteins. I. Two-dimensional mapping of human erythrocyte lysate proteins, Blood 53:1121-1132.

Giometti, C.S., N.G. Anderson, and N.L. Anderson, 1979, Muscle protein analysis. I. High resolution two-dimensional electrophoresis of skeletal muscle proteins for analysis of small biopsy samples, Clinical Chemistry 25:1877-1884.

Smith, C.F., N.L. Anderson, and N.G. Anderson, 1979, Mapping of rabbit skeletal muscle proteins by two-dimensional electrophoresis, Federation Proceedings 38:A3471, p. 888.

Willard, K.E., et al., 1979, Analytical techniques for cell fractions. XXVI. A two-dimensional electrophoretic analysis of basic proteins using phosphatidyl choline/urea solubilization, Analytical Biochemistry 100:289-298.

Giometti, C.S., et al., 1980, Analytical techniques for cell fractions. XXVI. Use of heart proteins as reference standards in two-dimensional electrophoresis, Analytical Biochemistry 102:47-58. 
Giometti, C.S., et al., 1980, Muscle protein analysis. II. Two-dimensional electrophoresis of normal and diseased human skeletal muscle, Clinical Chemistry 26:1152-1155.

Anderson, N.L., et al., 1981, The TYCHO system for computer analysis of two-dimensional gel electrophoresis patterns, Clinical Chemistry 27:1807-1820.

Danon, M.J., et al., 1981, Adult-onset nemaline rods in a patient treated for suspected dermatomyositis, Archives of Neurology 38:761-766.

Edwards, J.J., S.L. Tollaksen, and N.G. Anderson, 1981, Proteins of human semen. I. Twodimensional mapping of human seminal fluid, Clinical Chemistry 27:1335-1340.

Giometti, C.S., and N.G. Anderson, 1981, Muscle protein analysis. III. Analysis of solubilized frozen-tissue sections by two-dimensional electrophoresis, Clinical Chemistry 27:1918-1921.

Giometti, C.S., and N.L. Anderson, 1981, A variant of human nonmuscle tropomyosin found in fibroblasts by using two-dimensional electrophoresis, Journal of Biological Chemistry 256:11840-11846.

Taylor, J., N.L. Anderson, and N.G. Anderson, 1981, A computerized system for matching and stretching two-dimensional gel patterns represented by parameter lists, Electrophoresis '81, R. Allen, P. Arnaud, eds., W. deGruyter, Hawthorne, N.Y., pp. 383-400.

Tollaksen, S.L., J.J. Edwards, and N.G. Anderson, 1981, The use of carbamylated charge standards for testing batches of ampholyte used in two-dimensional electrophoresis, Electrophoresis 2:155-160.

Willard, K.E., and N.G. Anderson, 1981, Two-dimensional analysis of human lymphocyte proteins. I. An assay for lymphocyte effectors, Clinical Chemistry 27: 1327-1334.

Anderson, N.G., M.T. Powers, and S.L. Tollaksen, 1982, Proteins of human milk. I. Identification of major components, Clinical Chemistry 28:1045-1055.

Anderson, N.L., et al., 1982, A two-dimensional electrophoretic analysis of the heat shock-induced proteins of human cells, Clinical Chemistry 28:1084-1092.

Danon, M.J., C.S. Giometti, and N.G. Anderson, 1982, Analysis of proteins from human muscle biopsies by two-dimensional electrophoresis, Neurology 32:A203.

Edwards, J.J., S.L. Tollaksen, and N.G. Anderson, 1982, Proteins of human urine. III. Identification and two-dimensional electrophoretic map positions of some major urinary proteins, Clinical Chemistry 28:941-948. 
Edwards, J.J., et al., 1982, Proteins of human urine. II. Identification by two-dimensional electrophoresis of a new candidate marker for prostatic cancer, Clinical Chemistry 28:160-163.

Gemmell, M.A., and N.L. Anderson, 1982, Lymphocyte, monocyte, and granulocyte proteins compared by use of two-dimensional electrophoresis, Clinical Chemistry 28:1062-1066.

Giometti, C.S., 1982, Muscle protein analysis by two-dimensional gel electrophoresis, CRC Reviews in Clinical Laboratory Sciences 18:79-109.

Giometti, C.S., and N.L. Anderson, 1982, Tropomyosin heterogeneity in nonmuscle cells, Journal of Cell Biology 95:282a.

Giometti, C.S., K.E. Willard, and N.L. Anderson, 1982, Cytoskeletal proteins from human skin fibroblasts, peripheral blood leukocytes, and a lymphoblastoid cell line compared by twodimensional gel electrophoresis, Clinical Chemistry 28:955-961.

Giometti, C.S., M.J. Danon, and N.G. Anderson, 1983, Human muscle proteins: analysis by twodimensional electrophoresis, Neurology 33:1152-1156.

Giometti, C.S., and N.G. Anderson, 1984, Protein changes in activated human platelets, Clinical Chemistry 30:2078-2083.

Giometti, C.S., and N.L. Anderson, 1984, An electrophoretic variant of a human fibroblast protein with characteristics of smooth muscle tropomyosin, Journal of Molecular Biology 173:109-123.

Giometti, C.S., and N.L. Anderson, 1984, Tropomyosin heterogeneity in human cells, Journal of Biological Chemistry 259:14113-14120.

Tollaksen, S.L., N.L. Anderson, and N.G. Anderson, 1984, Operation of the ISO-DALT System, 7th ed., Argonne National Laboratory report ANL-BIM-84-1.

Anderson, N.G., et al., 1985, Two-dimensional electrophoretic analysis of wheat seed proteins, Crop Science 25:667-674.

Anderson, N.L., et al., 1985, Quantitative reproducibility of measurements from Coomassie bluestained two-dimensional gels: analysis of mouse liver protein patterns and a comparison of BALB/c and C57 strains, Electrophoresis 6:592-599.

Giometti, C.S., and M.J. Danon, 1985, Heterogeneity of human skeletal muscle tropomyosin, Annals of Neurology 18:234-243. 
Giometti, C.S., M.A. Gemmell, and N.L. Anderson, 1985, Two different variants of the same tropomyosin polypeptide in clones from GM1386 human skin fibroblasts, Biochemical and Biophysical Research Communications 128: 247-1253.

Giometti, C.S., et al., 1987, Detection of heritable mutations as quantitative changes in protein expression, Journal of Biological Chemistry 262:12764-12767.

Giometti, C.S., et al., 1988, A heritable variant of mouse liver ornithine aminotransferase (EC 2.6.1.13) induced by ethylnitrosourea, Journal of Biological Chemistry 263:15781-15784.

Giometti, C.S., et al., 1988, Heritable protein variants induced by exposure to ethylnitrosourea: heritability, subcellular location, and tissue distribution, Mutation Research 202:9-17.

Giometti, C.S., 1990, The current status of two-dimensional electrophoresis in germ cell mutation research, Mutation and the Environment, Part C, M.L. Mendelsohn and R. Albertini, eds., WileyLiss, New York, pp. 169-178.

Giometti, C.S., and M.J. Danon, 1990, The expression of myosin light chains and tropomyosin in human muscle biopsies with histochemical type 1 and type 2 fiber deficiency, Muscle and Nerve 13:209-214.

Giometti, C.S., et al., 1990, The analysis of recessive lethal mutations in mice by using twodimensional gel electrophoresis of liver proteins, Mutation Research 242:47-55.

Giometti, C.S., and J. Taylor, 1991, The application of two-dimensional electrophoresis to mutation studies, Advances in Electrophoresis, Vol. 4, M.J. Dunn, ed., VCH Verlagsgesellschaft, Weinheim, Germany, pp. 360-389.

Giometti, C.S., and J. Taylor, 1991, Quantitative changes in sets of proteins as markers of biological response, New Horizons in Biological Dosimetry, B.L. Gledhill and F. Mauro, eds., Wiley-Liss, New York, pp. 119-128.

Giometti, C.S., et al., 1991, A comparative study of the effects of clofibrate, ciprofibrate, WY-14,643, and di-(2-ethylhexyl)-phthalate on liver protein expression in mice, Applied and Theoretical Electrophoresis 2:101-107.

Giometti, C.S., et al., 1991, Quantitation of human leukocyte proteins after silver-staining: a study with two-dimensional electrophoresis, Electrophoresis 12:536-543. 
Giometti, C.S., J. Taylor, and S.L. Tollaksen, 1992, Mouse liver protein database: a catalog of proteins detected by two-dimensional gel electrophoresis, Electrophoresis 13:970-991.

Giometti, C.S., et al., 1992, Evidence for regulatory genes on mouse chromosome 7 that affect the quantitative expression of proteins in fetal and newborn liver, Proceedings of the National Academy of Sciences USA 89:2448-2452.

Taylor, J., and C.S. Giometti, 1992, Use of principal components analysis for mutation detection with two-dimensional electrophoresis protein separations, Electrophoresis 13:162-168.

Champion, K.M., et al., 1994, Identification of a heritable deficiency of the folate-dependent enzyme 10-formyltetrahydrofolate dehydrogenase in mice, Proceedings of the National Academy of Sciences USA 91:11338-11342.

Giometti, C.S., S.L. Tollaksen, and D. Grahn, 1994, Altered protein expression detected in the $F_{1}$ offspring of male mice exposed to fission neutrons, Mutation Research 320:75-85.

Giometti, C.S., et al., 1995, Analysis of proteins from human breast epithelial cells using twodimensional gel electrophoresis, Electrophoresis 16:1215-1224.

Giometti, C.S., et al., 1995, Two-dimensional gel electrophoresis mapping of proteins isolated from the hyperthermophile Pyrococcus furiosus, Journal of Chromatography A 698:341-349. 


\section{APPENDIX A:}

\section{WORK SAFETY}

1. All personnel involved in laboratory procedures must wear lab coats, safety glasses, and gloves. The gloves may be latex, vinyl, polycarbonate, nitrile, heavy rubber, or cotton, depending on the particular procedure or manipulation being performed. Refer to the Argonne Protective Glove Selection Guide for the appropriate choice.

2. No eating, drinking, or chewing gum is allowed in any laboratory. Smoking is not allowed in the building 202 .

3. Gloves should be worn during washing of dishes and tools, and hands must be washed before leaving the laboratory.

4. Magenta lab coats are required for work with isotopes in radioactive materials areas, but regular lab coats are approved for low-level radioactive work in controlled areas. Dosimeters must be obtained from Health Physics and used as directed.

5. The work area should be covered with plastic-backed absorbent paper when hazardous chemicals or radioactive materials are being used.

6. Disposable pipettes, beakers, and syringes should be used whenever possible. If not possible, label equipment as to possible contamination with radioactive or hazardous chemicals, and store in a designated area.

7. All work with radioisotopes, hazardous chemicals, or hazardous materials must be done in designated areas with appropriate signs posted.

8. Personnel must satisfy all Argonne-mandated training requirements including radiation safety, laboratory hazard communication, bloodborne pathogens, and waste generator training.

9. All flammable reagents (e.g., ethanol, methanol, 2-propanol) must be stored in the original containers in a flameproof cabinet. 


\section{APPENDIX B:}

\section{WASTE MANAGEMENT}

1. All animal waste (carcasses, blood products, etc.) are saved in disposal bags and placed in the drum in the walk-in refrigerated disposal room in the Animal Quarters wing. The appropriate disposal log must be filled out. Bloody surgical instruments are soaked overnight in diluted dish soap and $10 \%$ bleach and then rinsed thoroughly.

2. Animal tissue samples are prepared in a solution that solubilizes the proteins before loading them on the ISO. The components of this solution are generally consumed during electrophoresis when samples are analyzed. If excess sample is prepared, it is either stored in small tubes at $-70^{\circ} \mathrm{C}$ or disposed of as liquid chemical waste.

3. Excess human materials (body fluids or tissue pieces) are placed in biohazard bags and taken to the Health Division for autoclaving and disposal.

4. Hazardous chemical waste is collected in appropriately labeled and numbered polycarbonate bottles or steel drums, and log sheets are filled out after each entry of waste.

5. Radioactive waste is disposed of in the appropriate solid or liquid radioactive waste containers, and the log sheets are filled out.

6. Do not generate mixed waste (the mixture of radioactive and hazardous chemical waste) unless specifically allowed by an experimental procedure. 


\section{APPENDIX C:}

\section{RECIPES}

Recipe 1. SDS mix (solubilizing agent; blue tubes)

Compound
\begin{tabular}{|l|c|c|}
\hline $\begin{array}{l}\text { CHES (2-[N-cyclohexylamino]ethane } \\
\text { sulfonic acid) }\end{array}$ & $1 \mathrm{~g}$ & $0.5 \mathrm{M}$ \\
\hline SDS (sodium dodecyl sulfate) & $2 \mathrm{~g}$ & $2 \%$ \\
\hline DTT (dithiothreitol) & $1 \mathrm{~g}$ & $1 \%$ \\
\hline glycerol & $10 \mathrm{~mL}$ & $10 \%$ \\
\hline
\end{tabular}

- Adjust $\mathrm{pH}$ to 9.5 with $\mathrm{NaOH}$ and add water to make up to a final volume of $100 \mathrm{~mL}$.

Recipe 2. NP-40/urea mix (solubilizing agent; pink tubes)

Compound
\begin{tabular}{|l|c|c|}
\hline urea & Amount & Final Conc. \\
\hline Nonidet P-40 & $54 \mathrm{~g}$ & $9 \mathrm{M}$ \\
\hline $\begin{array}{l}\text { ampholyte, 8-10 range } \\
(20 \% \text { w/v stock) }\end{array}$ & $10 \mathrm{~mL}$ & $4 \%$ \\
\hline 2-mercaptoethanol & $2 \mathrm{~mL}$ & $2 \%$ \\
\hline
\end{tabular}

- Adjust $\mathrm{pH}$ to 9.5 with $\mathrm{NaOH}$ and add water to make up to a final volume of $100 \mathrm{~mL}$. 
Recipe 3. Urea mix without NP-40 (solubilizing agent; yellow tubes)

\begin{tabular}{l|c|c|} 
Compound & Amount & Final Conc. \\
\hline urea & $54 \mathrm{~g}$ & $9 \mathrm{M}$ \\
\hline $\begin{array}{l}\text { ampholyte, 3.5-10 range } \\
\text { (20\% w/v stock) }\end{array}$ & $5 \mathrm{~mL}$ & $2 \%$ \\
\hline 2-mercaptoethanol & $5 \mathrm{~mL}$ & $5 \%$ \\
\hline
\end{tabular}

- Adjust $\mathrm{pH}$ to 9.5 with $\mathrm{NaOH}$ and add water to make up to a final volume of $100 \mathrm{~mL}$.

Recipe 4. NP-40/urea/DTE mix (for muscle samples; green tubes)

\begin{tabular}{|c|c|c|}
\hline Compound & Amount & Final Conc. \\
\hline urea & $54 \mathrm{~g}$ & $9 \mathrm{M}$ \\
\hline Nonidet P-40 & $4 \mathrm{~mL}$ & $4 \%$ \\
\hline $\begin{array}{l}\text { ampholyte, } 3.5-10 \text { range } \\
\text { ( } 40 \% \text { w/v stock) }\end{array}$ & $5 \mathrm{~mL}$ & $2 \%$ \\
\hline DTE (dithioerythritol) & $1 \mathrm{~g}$ & $1 \%$ \\
\hline
\end{tabular}

- Adjust $\mathrm{pH}$ to 9.5 with $\mathrm{NaOH}$ and add water to make up to a final volume of $100 \mathrm{~mL}$. 
Recipe 5. $30 \%$ Acrylamide/1.8\% bis (for ISO setup and stacking gel)

\section{WARNING}

Preparation of stock acrylamide solutions (which are carcinogenic and neurotoxic) from crystalline chemicals must be done in the Carcinogen Laboratory. The working solution must be clearly labeled "DANGER: CANCER HAZARD" and be transported with secondary containment from the Carcinogen Lab to the laboratory where it is used. All personnel working with acrylamide must take the course on "Safe Handling of Carcinogens."

NOTE: When making a working solution in the Carcinogen Laboratory, any paper towels, used filter paper, gloves, shoe covers, and weighing materials must be disposed of in a drum in the waste room, and the waste must be logged on the waste sheet. Put waste acrylamide solutions in a beaker with excess ammonium persulfate and TEMED. Once the acrylamide has polymerized, it is nonhazardous and may be thrown in the trash. Any pipettes, gloves, or paper towels that contact acrylamide solutions are discarded in fiber drums as hazardous waste.

- In the Carcinogen Laboratory, mix

\begin{tabular}{l} 
Compound \\
\begin{tabular}{|l|c|c|}
\hline acrylamide & Amount & \multicolumn{1}{c|}{ Final Conc. } \\
\hline$N, N^{\prime}$-methylene-bis-acrylamide & $30 \mathrm{~g}$ & $.30 \%$ \\
\hline
\end{tabular} \\
\hline
\end{tabular}

- Add water to $100 \mathrm{~mL}$.

- Filter with a $115-\mathrm{mL}$ side-arm filter unit $\left(\mathrm{Nalgene}{ }^{\circledR}, 0.45 \mu \mathrm{m}\right)$ attached to the vacuum pump and store the solution in the refrigerator in a bottle marked "Danger: Cancer Hazard."

- Discard the filter unit in the dry carcinogen waste drum. 
Recipe 6. $10 \%$ Ammonium persulfate

- Dissolve $10 \mathrm{~g}$ of $\left(\mathrm{NH}_{4}\right)_{2} \mathrm{~S}_{2} \mathrm{O}_{8}$ in $100 \mathrm{~mL}$ of water.

- Store in the refrigerator in a brown bottle, and use the solution within one week.

Recipe 7. Equilibration buffer (recipe for $750 \mathrm{~mL}$ )

\begin{tabular}{|c|c|c|}
\hline Compound & Amount & Final Conc. \\
\hline glycerol & $75 \mathrm{~mL}$ & $10 \%$ \\
\hline Buffer II (recipe 8) & $375 \mathrm{~mL}$ & $50 \%$ \\
\hline SDS & $15 \mathrm{~g}$ & $2 \%$ \\
\hline $\begin{array}{l}\text { dithioerythritol } \\
\text { or } \\
\text { dithiothreitol } \\
\text { or } \\
\text { 2-mercaptoethanol }\end{array}$ & $\begin{array}{c}1.0 \mathrm{~g} \\
\text { or } \\
1.0 \mathrm{~g} \\
\text { or } \\
37.5 \mathrm{~mL}\end{array}$ & $5 \%$ \\
\hline bromophenol blue & $\begin{array}{l}\text { small } \\
\text { spatula-tip } \\
\text { full }\end{array}$ & trace \\
\hline
\end{tabular}

- Add $300 \mathrm{~mL}$ water.

- $\quad$ Adjust $\mathrm{pH}$ to 6.8 .

- Put the above ingredients directly into a convenient dispenser, such as the Repipet $\mathrm{Jr}$. (Fisher catalogue no. 13-687-59A).

* Mix approximately $1 \mathrm{~h}$ on a magnetic stirrer. 
Recipe 8. Buffer II (recipe for $375 \mathrm{~mL}$ )

\begin{tabular}{|c|c|c|}
\hline Compound & Amount & Final Conc. \\
\hline Trizma ${ }^{\circledR}$ base & $11.25 \mathrm{~g}$ & $3 \%$ \\
\hline SDS & $0.75 \mathrm{~g}$ & $0.2 \%$ \\
\hline
\end{tabular}

- Add $300 \mathrm{~mL}$ water.

- Mix chemicals on a stirrer and add $6 \mathrm{~N} \mathrm{HCl}$ until $\mathrm{pH}$ is 6.8 .

- Bring volume up to $375 \mathrm{~mL}$.

Recipe 9. Sucrose underlay solution

Do not use Coomassie blue because it drifts up to the bottom of the plates and leaves stains. A 50\% glycerol solution may be used as the underlay solution, but it is much more expensive than sucrose.

Compound
\begin{tabular}{|l|c|c|}
\hline sucrose & Amount & Final Conc. \\
\hline water & $100 \mathrm{~mL}$ & $35 \%$ \\
\hline $\begin{array}{l}\text { bromophenol blue or } \\
\text { methylene blue }\end{array}$ & trace & trace \\
\hline
\end{tabular}


Recipe 10. 27\% Acrylamide/0.8\% bis (for hand-poured DALT gels)

\section{WARNING}

Preparation of stock acrylamide solutions (which are carcinogenic and neurotoxic) from crystalline chemicals must be done in the Carcinogen Laboratory. The working solution must be clearly labeled "DANGER: CANCER HAZARD" and be transported with secondary containment from the Carcinogen Lab to the laboratory where it is used. All personnel working with acrylamide must take the course on "Safe Handling of Carcinogens."

NOTE: When making a working solution in the Carcinogen Laboratory, any paper towels, used filter paper, gloves, shoe covers, and weighing materials must be disposed of in a drum in the waste room, and the waste must be logged on the waste sheet. Put waste acrylamide solutions in a beaker with excess ammonium persulfate and TEMED. Once the acrylamide has polymerized, it is nonhazardous and may be thrown in the trash. Any pipettes, gloves, or paper towels that contact acrylamide solutions are discarded in fiber drums as hazardous waste.

- In the Carcinogen Laboratory, mix

\begin{tabular}{|l|c|c|}
\multicolumn{1}{l}{ Compound } & Amount & Final Conc. \\
\hline acrylamide & $300 \mathrm{~g}$ & $27 \%$ \\
\hline$N, N^{\prime}$-methylene-bis-acrylamide & $8 \mathrm{~g}$ & $0.8 \%$ \\
\hline
\end{tabular}

- Mix on a magnetic stirrer while bringing up to $1.1 \mathrm{~L}$ with water.

- Filter with a Nalgene ${ }^{\circledR}$ sterilization filter unit, $0.45 \mu \mathrm{m}$.

Recipe 11. Buffer L10

Compound

\begin{tabular}{|l|l|l|}
\hline Buffer L & 3 parts & $37.5 \%$ \\
\hline water & 5 parts & $62.5 \%$ \\
\hline
\end{tabular}


Recipe 12. Buffer L20

\begin{tabular}{|l|c|c|}
\multicolumn{1}{l|}{ Compound } & \multicolumn{1}{r|}{ Amount } & \multicolumn{1}{c|}{ Final Conc. } \\
\hline Buffer L & 3 parts & $75 \%$ \\
\hline glycerol & 1 part & $25 \%$ \\
\hline
\end{tabular}

Recipe 13. Water-saturated sec-butanol

\begin{tabular}{|l|c|c|}
\multicolumn{1}{l}{ Compound } & \multicolumn{1}{r|}{ Amount } & \multicolumn{1}{c|}{ Final Conc. } \\
\hline sec-butanol & $350 \mathrm{~mL}$ & $\sim 75 \%$ \\
\hline water & $100 \mathrm{~mL}$ & $\sim 25 \%$ \\
\hline
\end{tabular}

- Mix together and let stand until the butanol becomes clear. Make sure that there is a small water layer on the bottom. Otherwise, add more water or sec-butanol as appropriate.

Recipe 14. Photoflo overlay solution (for hand-poured gels)

This overlay is used to avoid using sec-butanol.

\begin{tabular}{|l|c|c|}
\multicolumn{1}{l}{ Compound } & Amount & \multicolumn{1}{c|}{ Final Conc. } \\
\hline Buffer L10 & $67 \mathrm{~mL}$ & $66.7 \%$ \\
\hline Water & $33 \mathrm{~mL}$ & $33.3 \%$ \\
\hline Photoflo & $0.1 \mathrm{~mL}$ & $0.1 \%$ \\
\hline
\end{tabular}


Recipe 15. Buffer L (recipe for $3 \mathrm{~L}$ )

\begin{tabular}{|c|c|c|}
\hline Compound & Amount & Final Conc. \\
\hline Trizma ${ }^{\circledR}$ base & $400 \mathrm{~g}$ & $13.3 \%$ \\
\hline Trizma ${ }^{\circledR} \mathrm{HCl}$ & $200 \mathrm{~g}$ & $6.7 \%$ \\
\hline
\end{tabular}

- Combine and add about $2 \mathrm{~L}$ of water.

- Add $\mathrm{HCl}$ until pH 8.5-8.6 is reached (approximately $120 \mathrm{~mL}$ of $6 \mathrm{~N} \mathrm{HCl}$ ).

- Add water up to $3 \mathrm{~L}$.

Recipe 16. Photoflo overlay solution (for computer-poured gels)

- Mix together

\begin{tabular}{|c|c|c|}
\hline Compound & Amount & Final Conc. \\
\hline Angel's buffer (recipe 17) & $16 \mathrm{~mL}$ & $16 \%$ \\
\hline water & $84 \mathrm{~mL}$ & $84 \%$ \\
\hline Photoflo & $0.1 \mathrm{~mL}$ & $0.1 \%$ \\
\hline
\end{tabular}

Recipe 17. Angel's buffer

\begin{tabular}{|l|c|c|}
\multicolumn{1}{l}{ Compound } & \multicolumn{1}{c}{ Amount } & \multicolumn{1}{c|}{ Final Conc. } \\
\hline Tris base & $870 \mathrm{~g}$ & $29.00 \%$ \\
\hline SDS & $22.5 \mathrm{~g}$ & $0.75 \%$ \\
\hline double-distilled water & $2.1 \mathrm{~L}$ & - \\
\hline
\end{tabular}

- Adjust $\mathrm{pH}$ to 8.6 with approximately $150-200 \mathrm{~mL}$ of $12 \mathrm{~N} \mathrm{HCl}$.

- Add water to make $3 \mathrm{~L}$. 
Recipe 18. Light acrylamide solution (12\%; for computer-poured DALT gels)

\section{WARNING}

Preparation of stock acrylamide solutions (which are carcinogenic and neurotoxic) from crystalline chemicals must be done in the Carcinogen Laboratory. The working solution must be clearly labeled "DANGER: CANCER HAZARD" and be transported with secondary containment from the Carcinogen Lab to the laboratory where it is used. All personnel working with acrylamide must take the course on "Safe Handling of Carcinogens."

NOTE: These solutions should be mixed in 3-L \#2026-4000 Nalgene ${ }^{\circledR}$ bottles set in a secondary container on the stirring plate in C106. After thorough mixing, the bottles are stored overnight at room temperature in C114. The bottle label should read "LIGHT ACRYLAMIDE (12\%) - DANGER: CANCER HAZARD."

\begin{tabular}{|c|c|c|}
\hline Compound & $\begin{array}{l}\text { Amount } \\
(\mathrm{mL})\end{array}$ & Final Conc. \\
\hline \multicolumn{3}{|l|}{ For $1 \mathrm{~L}$ final volume: } \\
\hline acrylamide ( $40 \%$ solution) $)^{\mathrm{a}}$ & 300 & $12 \%$ \\
\hline water & 670 & - \\
\hline glycerol & 30 & $3 \%$ \\
\hline \multicolumn{3}{|l|}{ For $1.5 \mathrm{~L}$ final volume: } \\
\hline acrylamide ( $40 \%$ solution) $)^{\mathrm{a}}$ & 450 & $12 \%$ \\
\hline water & 1005 & 一 \\
\hline glycerol & 45 & $3 \%$ \\
\hline \multicolumn{3}{|l|}{ For 2 L final volume: } \\
\hline acrylamide ( $40 \%$ solution) $)^{a}$ & 600 & $12 \%$ \\
\hline water & 1340 & 一 \\
\hline glycerol & 60 & $3 \%$ \\
\hline
\end{tabular}

${ }^{a}$ Commercial, pre-mixed acrylamide/bis formulation. 
Recipe 19. Heavy acrylamide solution (22.46\%; for computer-poured DALT gels)

\section{WARNING}

Preparation of stock acrylamide solutions (which are carcinogenic and neurotoxic) from crystalline chemicals must be done in the Carcinogen Laboratory. The working solution must be clearly labeled "DANGER: CANCER HAZARD" and be transported with secondary containment from the Carcinogen Lab to the laboratory where it is used. All personnel working with acrylamide must take the course on "Safe Handling of Carcinogens."

NOTE: These solutions should be mixed in 3-L \#2026-4000 Nalgene ${ }^{\circledR}$ bottles set in a secondary container on the stirring plate in C106. After thorough mixing, the bottles of solutions are stored overnight at room temperature in C114. The bottle label should read "HEAVY ACRYLAMIDE (22.5\%) — DANGER: CANCER HAZARD."

\begin{tabular}{|c|c|c|}
\hline Compound & $\begin{array}{l}\text { Amount } \\
(\mathrm{mL})\end{array}$ & Final Conc. \\
\hline \multicolumn{3}{|l|}{ For $1 \mathrm{~L}$ final volume: } \\
\hline acrylamide ( $40 \%$ solution $)^{\mathrm{a}}$ & 561.5 & $22.46 \%$ \\
\hline water & 308.5 & - \\
\hline glycerol & 130 & $13 \%$ \\
\hline \multicolumn{3}{|l|}{ For $1.5 \mathrm{~L}$ final volume: } \\
\hline acrylamide ( $40 \%$ solution) $^{\mathrm{a}}$ & 842.25 & $22.46 \%$ \\
\hline water & 462.75 & - \\
\hline glycerol & 195 & $13 \%$ \\
\hline \multicolumn{3}{|l|}{ For $2 \mathrm{~L}$ final volume: } \\
\hline acrylamide ( $40 \%$ solution) ${ }^{\mathrm{a}}$ & 1123 & $22.46 \%$ \\
\hline water & 617 & - \\
\hline glycerol & 260 & $13 \%$ \\
\hline
\end{tabular}

a Commercial, pre-mixed acrylamide/bis formulation. 
Recipe 20. Ammonium persulfate (for computer-poured DALT gels)

NOTE: "Light" and "heavy" persulfate solutions are so called becauise they are used, respectively, with the light or heavy acrylamide solutions.

- "Light" persulfate solution: Take $25 \mathrm{~mL}$ of $10 \%\left(\mathrm{NH}_{4}\right)_{2} \mathrm{~S}_{2} \mathrm{O}_{8}$ solution (recipe 6) and make up to $100 \mathrm{~mL}$ with water (final concentration, $2.5 \% \mathrm{w} / \mathrm{v}$ ).

- "Heavy", persulfate solution: Take $14 \mathrm{~mL}$ of $10 \%\left(\mathrm{NH}_{4}\right)_{2} \mathrm{~S}_{2} \mathrm{O}_{8}$ solution (recipe 6) and make up to $100 \mathrm{~mL}$ with water (final concentration, $1.4 \% \mathrm{w} / \mathrm{v}$ ).

Recipe 21. TEMED (for computer-poured DALT gels)

NOTE: Make dilutions immediately before use from the concentrated reagent.

- "Light" TEMED solution: Take $230 \mu \mathrm{L}$ of TEMED and make up to $100 \mathrm{~mL}$ with water (final concentration, $0.23 \% \mathrm{v} / \mathrm{v}$ ).

- "Heavy" TEMED solution: Take $30 \mu \mathrm{L}$ of TEMED and make up to $100 \mathrm{~mL}$ with water (final concentration, $0.03 \% \mathrm{v} / \mathrm{v}$ ).

Recipe 22. Stacking gel mix

Compound
\begin{tabular}{|l|c|c|}
\hline Buffer II (recipe 8) & Amount & Final Conc. \\
\hline water & $480 \mathrm{~mL}$ & $48 \%$ \\
\hline $\begin{array}{l}30 \% \text { acrylamide/1.8\% bis solution } \\
\text { (recipe 5) }\end{array}$ & $380 \mathrm{~mL}$ & - \\
\hline
\end{tabular}


Recipe 23. Agarose running buffer (when stacker is not used)

\begin{tabular}{|c|c|c|}
\hline Compound & Amount & Final Conc. \\
\hline Trizma ${ }^{\circledR}$ base & $3 \mathrm{~g}$ & $0.3 \%$ \\
\hline glycine & $14.4 \mathrm{~g}$ & $1.44 \%$ \\
\hline SDS & $1 \mathrm{~g}$ & $0.1 \%$ \\
\hline agarose & $5 \mathrm{~g}$ & $0.5 \%$ \\
\hline
\end{tabular}

- Add water to $1 \mathrm{~L}$.

\section{WARNING}

Be sure the cap of the agarose flask is loose or off during microwaving. Agarose solutions often superheat when they are microwaved, boiling over when disturbed, e.g., when a pipette is introduced, and serious injury can result. Use extreme caution when handling heated agarose. Direct the flask away from you when starting to use the solution.

- Microwave to dissolve.

- Freeze in $100-\mathrm{mL}$ portions.

Recipe 24. DALT buffer

Compound
\begin{tabular}{|c|c|c|}
\hline For 26-L tank: & Amount & Final Conc. \\
\hline Tris & $78 \mathrm{~g}$ & $24 \mathrm{mM}$ \\
\hline glycine & $374 \mathrm{~g}$ & $0.2 \mathrm{M}$ \\
\hline SDS & $26 \mathrm{~g}$ & $3.5 \mathrm{mM}$ \\
\hline For 33-L tank: & & \\
\hline Tris & $100 \mathrm{~g}$ & $24 \mathrm{mM}$ \\
\hline glycine & $475 \mathrm{~g}$ & $0.2 \mathrm{M}$ \\
\hline SDS & $33 \mathrm{~g}$ & $3.5 \mathrm{mM}$ \\
\hline
\end{tabular}

- Add approximately $4 \mathrm{~L}$ distilled water and stir with a magnetic stirrer until dissolved.

- Add to the clean DALT tank and fill with distilled water to the proper mark. 
Recipe 25. Coomassie blue stain

\begin{tabular}{|c|c|c|}
\hline Compound & Amount & Final Conc. \\
\hline Coomassie blue & $40 \mathrm{~g}$ & $0.2 \%$ \\
\hline double-distilled water & $9.5 \mathrm{~L}$ & 一 \\
\hline $\mathrm{H}_{3} \mathrm{PO}_{4}$ & $250 \mathrm{~mL}$ & $2.1 \%$ \\
\hline ethanol (95\% solution) & $10 \mathrm{~L}$ & $50 \%$ \\
\hline
\end{tabular}

- Mix the blue stain and the water. Add a 500-mL of concentrated (85\%) $\mathrm{H}_{3} \mathrm{PO}_{4}$.

- Add $10 \mathrm{~L}$ of $95 \%$ ethanol and mix thoroughly with a motor-driven stirrer for $1 \mathrm{~h}$.

- Let the solution stand overnight before use. Filtering is not necessary.

Recipe 26. Bovine serum albumin blocking solution

Compound
\begin{tabular}{|l|c|c|}
\hline Tris buffer (1 M, pH 7.5; recipe 27) & $5 \mathrm{~mL}$ & $10 \mathrm{mM}$ \\
\hline bovine serum albumin & $50 \mathrm{~mL}$ & $10 \%$ \\
\hline
\end{tabular}

NOTE: Use sterile procedures when handling bovine serum albumin (BSA) to minimize bacterial contaminants.

- Add saline solution (recipe 28) to make up a final volume of $500 \mathrm{~mL}$. Adjust $\mathrm{pH}$ to 7.4-7.6.

Recipe 27. $1 \mathrm{M}$ Tris buffer

- Dissolve $12.1 \mathrm{~g}$ of Tris in water; adjust $\mathrm{pH}$ to 7.5 and make up to a final volume of $100 \mathrm{~mL}$. 
Recipe 28. Saline solution

\begin{tabular}{|c|c|c|}
\hline Compound & Amount & Final Conc. \\
\hline $\mathrm{NaCl}$ & $90 \mathrm{~g}$ & $0.15 \mathrm{M}$ \\
\hline water & $10 \mathrm{~L}$ & - \\
\hline
\end{tabular}

Recipe 29. Nonfat dry milk blocking solution

\begin{tabular}{|c|c|c|}
\hline Compound & Amount & Final Conc. \\
\hline powdered milk & $3 \mathrm{~g}$ & $3 \%$ \\
\hline Tris buffer ( $1 \mathrm{M}, \mathrm{pH} 7.5$; recipe 27$)$ & $1 \mathrm{~mL}$ & $10 \mathrm{mM}$ \\
\hline
\end{tabular}

- Add saline solution (recipe 28 ) to make a final volume of $100 \mathrm{~mL}$.

Recipe 30. Tris/saline solution

- Add $1 \mathrm{~mL}$ of $1 \mathrm{M}$ Tris (recipe 27) to $100 \mathrm{~mL}$ of saline solution (recipe 28 ) to make the $10 \mathrm{mM}$ Tris/solution. 


\section{APPENDIX D:}

\section{AMPHOLYTE EVALUATION}

This section on ampholyte evaluation presents a method for checking different ampholyte mixtures before proceeding in depth into research on new samples. There is no one perfect ampholyte that produces perfect results for all different kinds of samples. An ISO apparatus can be modified so that there are two rows of 10 tubes, each spaced to allow a small centrifuge tube to fit over the bottom of each two ISO tubes. Thus, each of the 10 centrifuge tubes can contain a different ampholyte mixture.

1. Set up the apparatus and tubes. Mix in a lyophilization flask:

Compound
\begin{tabular}{|l|c|}
\hline urea & Amount \\
\hline double-distilled water & $16.8 \mathrm{~mL}$ \\
\hline $\begin{array}{l}30 \% \text { acrylamide } 1.8 \% \text { bis solution } \\
\text { (recipe 5) }\end{array}$ & $4.6 \mathrm{~mL}$ \\
\hline
\end{tabular}

2. Warm the flask to room temperature to dissolve the urea. Degas with a vacuum pump. Add $0.8 \mathrm{~mL}$ of NP-40 and swirl carefully.

3. Aliquot $3.5 \mathrm{~mL}$ of the solution into each of the 10 mixing tubes.

4. Add $188 \mu \mathrm{L}$ of the ampholyte mixture per tube, using one type of ampholyte, or a mixture of more than one brand, or a narrow-range plus a wide-range ampholyte, to make 10 combinations.

5. Add $11.7 \mu \mathrm{L}$ of ammonium persulfate per tube and mix.

6. Add $3 \mu \mathrm{L}$ of TEMED dilution (made by adding $15 \mu \mathrm{L}$ of TEMED to $30 \mu \mathrm{L}$ of $\mathrm{H}_{2} \mathrm{O}$ ). Mix carefully and pour into the tubes attached to the ISO apparatus.

7. Place the ISO apparatus on the electrode stand. Carefully overlay acrylamide solutions with double-distilled water until each tube is filled. Gently lower the entire apparatus into the ISO chamber filled with water.

8. Allow to polymerize for 1-2 h. Remove the centrifuge which contained the polymerization mix, clean the apparatus, and prefocus as usual. 
9. Load the samples. Preferably, load the same sample onto each different ampholyte mix so that results can be compared.

10. Run the gels, stain with Coomassie blue, and compare. 


\section{APPENDIX E:}

\section{MISCELLANEOUS PROCEDURES}

Procedure 1. Preparation of creatine phosphokinase charge standards

\begin{tabular}{l|c|c|}
\multicolumn{1}{l}{ Compound } & Amount & Final Conc. \\
\hline rabbit muscle creatine phosphokinase & $5 \mathrm{mg}$ & $5 \mathrm{mg} / \mathrm{mL}$ \\
\hline NP-40/urea mix (recipe 2) & $1 \mathrm{~mL}$ & - \\
\hline
\end{tabular}

- $\quad$ Aliquot the solution into seven tubes.

- Do not heat the first tube. Heat each of the remaining six tubes for $4,6,8,10,12$, and 15 minutes at $95^{\circ} \mathrm{C}$ in a heating block. At the end of each time period, place the appropriate tube in an ice bucket.

- The contents of these seven tubes are then mixed together and $50 \mu \mathrm{L}$ of the mix is put into small microfuge tubes for storage at $-70^{\circ} \mathrm{C}$.

- Thaw out a tube for each experiment and load $2 \mu \mathrm{L}$ of the mix on top of each ISO tube containing the protein sample to be run.

Alternatively, $110 \mathrm{mg}$ of creatine phosphokinase in $22 \mathrm{~mL}$ can be used to make a one-year supply of standard. Charge standards can now also be purchased from Pharmacia (catalogue no.17-0582-01).

Procedure 2. ID number tags for DALT gels

Connect to anbiw8.

Run tycho_e:[exe]angelnos.

Answer the questions asked, and get the file named "angelnos.txt."

- Load the cut filter paper into the printer paper drawer before you enter the print command!

- To print the numbers, type

print $/$ que $=$ Izrland gelnos. txt

Identification numbers may also be made on the typewriter by using filter paper and a carbon ribbon. 
Procedure 3. Preparation of rat heart molecular weight standards

- Sacrifice the rat by decapitation and perfuse heart with cold phosphate-buffered saline (PBS).

- $\quad$ Remove the heart, place it into a tared beaker containing cold PBS, and weigh it.

- Dry the heart with blotter paper, place it into SDS homogenization buffer (1\% SDS, $0.5 \%$ DTT, $0.125 \mathrm{M}$ Tris- $\mathrm{HCl}, \mathrm{pH} 6.8$ ), and mince it with scissors.

- Mix the minced tissue with additional buffer to yield a $5 \%$ homogenate $(5 \mathrm{~g}$ of tissue per $100 \mathrm{~mL}$ homogenate) and mix at $4{ }^{\circ} \mathrm{C}$ for $30 \mathrm{~s}$ at full speed in a chilled Waring blender.

- Filter the homogenate through two layers of cheese cloth and mix with a stock agarose solution (1.4\% agarose in the SDS homogenization buffer) to yield mixtures containing from 2.5 to $20 \mathrm{mg}$ of tissue per millimeter of $0.7 \%$ agarose.

- $\quad$ Freeze in $5-\mathrm{mL}$ aliquots and store at $-20^{\circ} \mathrm{C}$ or $-70^{\circ} \mathrm{C}$. 


\section{DISTRIBUTION FOR ANL-96/19}

Internal

ANL Technical Publications Services

D.E. Nadziejka (6)

G. Griparis (2)

C.S. Giometti (50)

\section{External}

U.S. Department of Energy Office of Scientific and Technical Information (2) Manager, U.S. Department of Energy Chicago Field Office

ANL-E Libraries

ANL-W Library 